\title{
LA GESTIÓN DEL AGUA EN LA CIUDAD ROMANA DE LACIPO (CASARES, MÁLAGA)
}

\section{THE WATER MANAGEMENT IN THE ROMAN CITY OF LACIPO (CASARES, MÁLAGA)}

\author{
MARÍA DEL MAR CASTRO GARCÍA \\ Investigadora posdoctoral Marie Curie european individual fellow. Dipartimento di Scienze Storiche e dei Beni Culturali \\ Università di Siena (Italia). Via Roma 65 (Sede dei Servi). 53100 Siena (SI) Italia \\ Correo-e: mariadel.castro@unisi.it. (D) https://orcid.org/0000-0002-9159-3096 \\ Researcher ID: <https://publons.com/researcher/AAG-6975-2019>
}

\begin{abstract}
Resumen: Lacipo es una ciudad romana de modestas dimensiones que se extiende sobre un cerro que controla el valle del río Genal-Guadiaro, próximo al litoral mediterráneo, en la provincia Baetica. Entre los restos arqueológicos que se conservan, destaca un conjunto de estructuras hidráulicas diseminadas por el propio cerro y por el territorio circundante. El examen detallado de estas construcciones permite conocer los métodos de gestión del agua empleados en este centro urbano, reconstruyendo el sistema de abastecimiento de aguas desde su captación, conducción, distribución, almacenaje y sus posteriores usos. Este análisis demuestra cómo el agua era un recurso necesario y valioso para la ciudad, y que para garantizar su abundancia los habitantes de Lacipo no dudaron en captar manantiales de calidad en las proximidades y conducirlos diversos kilómetros para poder desarrollar las actividades públicas y privadas propias de una civitas romana.
\end{abstract}

Palabras clave: Baetica, ciclo del agua, hidráulica, cisterna, acueducto, civitas.

\section{INTRODUCCIÓN}

Lacipo (cerro Alechipe o cerro Pellizcoso, Casares, Málaga) es una civitas stipendiaria del conventus
Abstract: Lacipo is a small Roman town situated on a hill that overlooks the fluvial valley of Genal-Guadiaro, next to the Mediterranean coast, in the province of Baetica. In amongst the archaeological remains that are conserved on the site, a group of hydraulic structures are particularly notable. They are scattered around the hill and the surrounding countryside. Examination of these constructions has allowed us to study the urban water resources management, through the reconstruction of the water supply system: collecting, carrying, storing, distributing, and the subsequent usage. The analysis shows that water was a necessary and valuable resource for the city in order to guarantee it. The inhabitants of Lacipo did not hesitate to collect quality spring water from the surrounding area and transport it over several kilometres to be able to develop the public and private activities of a Roman civitas.

Key words: Baetica, water cycle, hidraulic, cisterns, aqueduct, civitas.

Gaditanus, en la provincia Baetica (Plin. Nat. 3.15.; otros autores que citan Lacipo: Mela 2.93.; Ptol. Geog. 2.4.11.). Se ubica en un cerro amesetado sobre una de las laderas meridionales de la sierra de Crestellina, una 


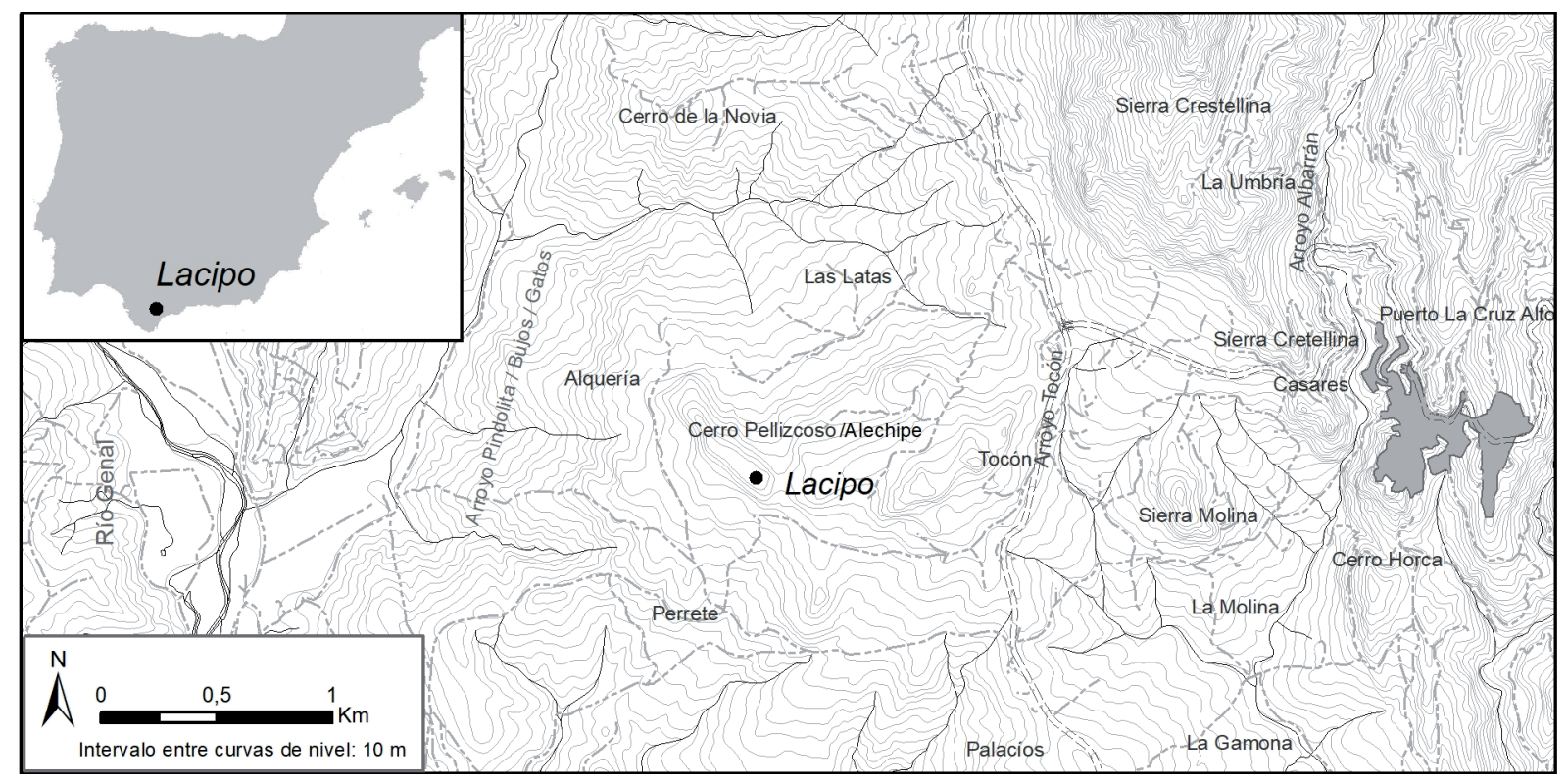

Figura 1. Situación geográfica de la ciudad romana de Lacipo.

de las últimas estribaciones de la serranía de Ronda. Próxima a la costa mediterránea y al estrecho de Gibraltar, desde su emplazamiento controla el valle del río Genal en su confluencia con el Guadiaro, el cual constituiría una vía de comunicación entre la costa y el interior. El topónimo porta el sufijo ipo/-ippo, interpretado como indicador de "ciudad", "lugar habitado" (Villar 2000: 118). Esta particularidad ha sido tomada como prueba de la existencia de una ciudad indígena que toma contacto con Roma a fines del siglo III a.C. (Rodríguez Oliva 2017: 54-55). También se ha propuesto su inclusión en un ámbito de influencia cultural púnicocartaginés por su proximidad a los asentamientos costeros del Estrecho (Bravo 2010: 171).

Lacipo tuvo una temprana importancia, como evidenciaría su ceca tardorrepublicana (Mora 1990: 8, Corzo 2005). Igualmente, se apuntan posibles vínculos de sus habitantes con los primeros colonos de Carteia (171 a.C.) (Rodríguez Oliva 2006). La ciudad contó con instituciones político-administrativas, constatadas por los testimonios epigráficos que hacen referencia a un ordo decuriorum y una res publica (CIL II 1934 y 1936), y religiosas, con referencias a libertos desempeñando cargos de sacerdocio dedicado al culto imperial (CIL II 1934-1935). El contenido de estas inscripciones no permite una datación precisa, pero esta práctica religiosa remite a los siglos I-III d.C. (Fishwick 1993). Posiblemente, la ciudad deba su existencia al control territorial que ejerce desde su posición: por un lado, en el acceso del litoral al interior, a través del valle fluvial, y por otro, como centro cívico de la población dispersa que se extiende en su territorium.

Las únicas investigaciones arqueológicas sistemáticas en el asentamiento se remiten a los años setenta del siglo pasado (Puertas 1982). Durante varias campañas, dos sectores del cerro (norte y sur) fueron excavados. En el sector sur se documentó un gran edificio, posiblemente de carácter público, y en el norte restos de construcciones de carácter defensivo. Todo el conjunto fue datado en los siglos I-II d.C. Testimonios epigráficos parecen confirmar la existencia de edificios religiosos (AE 1981 504; CIL II 1934, 1935, 1936; CIL II²/7 259). Sin embargo, la parte habitacional no se ha constatado arqueológicamente.

\section{EL ABASTECIMIENTO DE AGUA: LA CAPTACIÓN Y CONDUCCIÓN DEL AGUA CORRIENTE, EL ACUEDUCTO}

El agua es un recurso esencial para una ciudad romana, siendo fundamental no solo para las necesidades humanas básicas, sino también para el desarrollo de las distintas funciones cívicas, religiosas, higiénicas o lúdicas (véase Malissard 1994). Lacipo, al estar situada en altura, no dispone de fuentes susceptibles de ser explotadas. Los pequeños arroyos que la circundan son limitados y muy estacionales. Además, se encuentra 
alejada y a una diferencia de altura importante del río Genal. Por ello debe buscar otras alternativas. Por un lado recurre a la captación y almacenamiento de agua de lluvia, en una zona donde las precipitaciones se concentran en determinadas épocas del año. Posteriormente busca manantiales de calidad susceptibles de ser captados y conducidos hasta el núcleo urbano. Para ello emplea diversas soluciones constructivas propias de la ingeniería hidráulica romana. Una vez en la ciudad, el agua debía ser convenientemente distribuida a los edificios y fuentes públicas, y destinada a los diversos usos públicos o privados. Finalmente, el agua usada debía ser evacuada (sobre el ciclo de agua en la ciudad romana consúltese: Front. Aq., Eschebach 1977, Bruun 1991, Hodge 1992, Ricciardi y Scrinari 1996, Dessales 2013).

Los testimonios materiales conservados en el yacimiento, visibles en la actualidad, nos permiten reconstruir en parte el ciclo urbano del agua. El objetivo inicial de esta investigación fue el estudio del empleo de prácticas de gestión a través de una planificación ejercida por un municipio romano de modestas dimensiones y relevancia local. Para ello, realizamos una serie de visitas al yacimiento con el fin de documentar las construcciones hidráulicas. Estos resultados, junto con la información aportada por las excavaciones practicadas en el sitio y por algún estudio previo relativo a la ciudad romana en general, y a su abastecimiento de agua en particular (Soto Jiménez 1979, Navarro 2006, Tomassetti et al. 2016, Sánchez y Martínez 2016), nos han permitido plantear las hipótesis expuestas en este trabajo.

La primera descripción del acueducto de Lacipo la aporta L. Soto Jiménez (1979). Posteriormente, la conducción ha sido mencionada en diversos trabajos (Navarro 2006, Sánchez y Martínez 2016: 208, Tomassetti et al. 2016). Sin embargo, hasta el momento no se ha llevado a cabo un análisis en profundidad de su trazado.

En cuanto al caput aquae, L. Soto Jiménez (1979) señala la Fuente Grande como posible lugar de captación. La localización del manantial es problemática, ya que no aparece en la cartografía actual. Tampoco se incluye en los inventarios de fuentes y manantiales oficiales (Proyecto Conoce tus Fuentes, <http:/www. conocetusfuentes.com>). En cambio, en 1967 fue derivada para abastecer al municipio de Casares (Saborido 2006: 96). Otro manantial, la fuente de la Arquita, localizado más al sur, en el "camino de las Viñas", también ha sido empleado en el suministro hídrico de la actual localidad (Saborido 2006: 96). Asimismo, la tradición oral del lugar habla sobre la abundancia y riqueza de la
Fuente Grande, pudiendo ser este el motivo de su atribución como cabecera del acueducto. Lo cierto es que toda esta zona es rica en agua, tal y como demuestra la presencia de otros manantiales y de abundantes pozos. Además, es el área desde la que se condujo el agua para el primer abastecimiento a Casares en el siglo XVIII (Saborido 2006: 96).

La ubicación aproximada de la Fuente Grande se ha establecido siguiendo la información aportada por un bosquejo planimétrico de 1875 (Casares, Planimetría 1875). En él aparece el topónimo "Cortijo Fuente Grande", situado en la ribera izquierda del arroyo de la Albarrada o Albarrá, en la ladera del macizo Matagallar. Entendemos que este cortijo tuvo que ser la propiedad que albergaba la fuente. El topónimo se emplaza a una cota aproximada de entre 495 y 500 m s.n.m., es decir, a una altura superior al yacimiento de Lacipo (328 m s.n.m.). Del mismo modo, los primeros vestigios de specus sobre substructio documentados, situados en la ladera opuesta de la Sierra Crestellina, se encuentran a una cota de $430 \mathrm{~m}$ s.n.m.

El manantial desapareció como consecuencia de alteraciones sufridas en época contemporánea, sin poder comprobar la existencia de restos que ratifiquen su vinculación como cabeza de captación del acueducto. Sin embargo, la fuente de la Arquita continúa manando agua de calidad. Por ello, la hemos considerado otro posible punto de captación de aguas para el acueducto. Aunque se encuentra un poco más alejada de la Fuente Grande $(1.500 \mathrm{~m})$, se sitúa en una cota susceptible de ser conducida (450 m s.n.m.). Para enlazar con la substructio documentada en la ladera opuesta debe mantener una pendiente constante.

En función de la topografía y de los escasos restos documentados in situ, presentamos un trazado hipotético del acueducto. Este recorrido propuesto es limitado, ya que falta información necesaria para poder precisar y determinar las soluciones constructivas empleadas en los distintos tramos. El principio de un acueducto es conducir agua entre dos puntos, el de captación y el de destino. El caput aquae debe situarse a una altura superior que el lugar de llegada, ya que a través de un canal, el agua circula por gravedad. Así, el $l i-$ brator debía nivelar el recorrido con mucha precisión, consiguiendo una pendiente suficiente para que el agua llegase a su destino, sin mucha velocidad para que no dañase la obra. El canal o specus, empleando diversas soluciones constructivas según fuera más conveniente (subterráneo, semienterrado, elevado sobre muro o substructio, elevado sobre arcuationes o pilares, a presión mediante sifón, etc.), avanzaba adaptándose a la 
topografía del terreno (Fabre et al. 1991, Hodge 1992, Sánchez y Martínez 2016: 37-38).

En el caso concreto del acueducto de Lacipo, los primeros restos documentados se sitúan en la ribera derecha del arroyo la Albarrada. La conducción, desde el caput aquae, debía atravesar el curso de agua en algún punto. Para ello emplearía alguna solución constructiva para salvar el obstáculo, probablemente arcuationes (Hodge 1992: 129-147). El arroyo normalmente lleva agua durante todo el año, con importantes crecidas en invierno. Sin embargo, su lecho no es ancho, lo que demuestra el ojo del pequeño puente erigido para su cruce, denominado popularmente "puente romano". En cambio, la técnica empleada en su construcción no pertenece a esta cronología. Tras la inspección del lugar no detectamos restos del acueducto.

Como hemos comentado, encontramos los primeros restos de la conducción en la ladera opuesta al emplazamiento del caput, tras cruzar el arroyo. La técnica constructiva empleada es el canal sobre substructio. Esta es una de las soluciones constructivas más empleada en los acueductos romanos (Hodge 1992: 129). Se traduce en un specus elevado sobre murete, en este caso adosado a la pared de la ladera por la que discurre. Situado aproximadamente a $430 \mathrm{~m}$ s.n.m., presenta unas dimensiones de $1 \mathrm{~m}$ de altura y $0,55 \mathrm{~m}$ de ancho. Está realizado en conglomerado de piedras y mortero de cal (fig. 3). En su parte superior sustentaría el specus, que no se ha conservado. Habitualmente el canal está protegido por una cubierta realizada en diversos materiales, sin embargo no hemos hallado indicios que prueben su existencia.

El acueducto continúa su trazado en dirección sur. Debido al desnivel que adquiere el terreno a modo de barranco, el specus discurre sobre un paredón. Está realizado con el mismo aparejo que la substructio, empleando sillarejos pequeños bien careados trabados con mortero y escuadrados, formando una pared lisa. Alterna una serie de pilares adosados a modo de contrafuertes para reforzarlo (fig. 4). Esta solución se utiliza debido al relieve accidentado por el que discurre la obra, con el objeto de mantener la pendiente del canal. La conducción prosigue adosada a esta vertiente de la sierra de Crestellina, discurriendo en dirección a Casares y más concretamente a Lacipo.

Avanzando en su recorrido fueron detectados restos del specus in situ. Se encontraba fracturado, lo que impidió tomar sus medidas. Revestido con opus signinum, conserva el cuarto de bocel en sus ángulos (fig. 5). En esa pared, que sirve de sustento del canal y de contención del barranco de la montaña, localizamos una rotura. Esta nos permitió observar con detalle el adosamiento del muro de contención a la pendiente natural, con un grosor de 1,30 m aproximadamente (fig. 6C). En algunas de sus partes, la obra conserva un enlucido exterior alisado a modo de revestimiento final que sirve para darle consistencia al sillarejo y mejorar su apariencia (fig. 6A).

Más adelante el muro continúa. No obstante, los pilares se encuentran exentos en este tramo, separados unos $4 \mathrm{~m}$ de la pared (fig. 7). En algunos de ellos se conservan restos de signinum en la parte superior. Estos pilares podrían sustentar el canal, según indicaría el mortero hidráulico. El muro de contención evitaría desprendimientos de la ladera superior, que dañasen la fila paralela de pilares exentos. Otra posibilidad es que hubieran sido pilares para arcos que sirvieran de contrafuertes a la pared construida, que sostendría el canal. Así se aliviaría el empuje de la ladera. Por otra parte, el muro, realizado a base de sillarejos, se adosa a la montaña. Las rocas calizas que sobresalen se tallan para formar ángulos rectos y permitir el acoplamiento de la construcción (fig. 6B).

Otro detalle constructivo del acueducto es la inserción de aliviaderos o desagües en la pared de mampuestos para canalizar escorrentías, evitando así el deterioro de la obra por las aguas procedentes de cotas superiores. Estos aliviaderos son triangulares, en forma de cubierta a dos aguas, y se sitúan en la parte inferior del muro (fig. 6D).

En el avance de la conducción por la vertiente este de la sierra Crestellina hacia el sur, a una altura de 418-420 m s.n.m., observamos el empleo de otra técnica constructiva. Debido a la naturaleza caliza del terreno y sus afloramientos rocosos, los salientes de la pendiente son utilizados para tallar el canal. El specus presenta unas dimensiones de $0,35 \mathrm{~m}$ de ancho y $0,65 \mathrm{~m}$ de alto, conservando huellas de talla (fig. 8). El canal excavado en la roca es una técnica minoritaria empleada en los acueductos romanos (Hodge 1992: 105-106). En general se utiliza en zonas montañosas o poco pobladas, incluso es muy usual encontrarla en conducciones destinadas a usos agrícolas e industriales. En cambio, en Hispania sí que contamos claros ejemplos de canales excavados en la roca destinados a abastecer ciudades: particularmente en la Tarraconensis, en el acueducto de Albarracín-Cella (Teruel) (Almagro 2002), en el acueducto de los Bañales (Uncastillo, Zaragoza), que incluso alberga una tubería cerámica o metálica en su interior (Beltrán 1977: 95-101), o en el acueducto de Peña Cortada (Tuéjar, Valencia) (Jiménez 1995). En Baetica, este tipo de canales se ha documentado en lugares como 


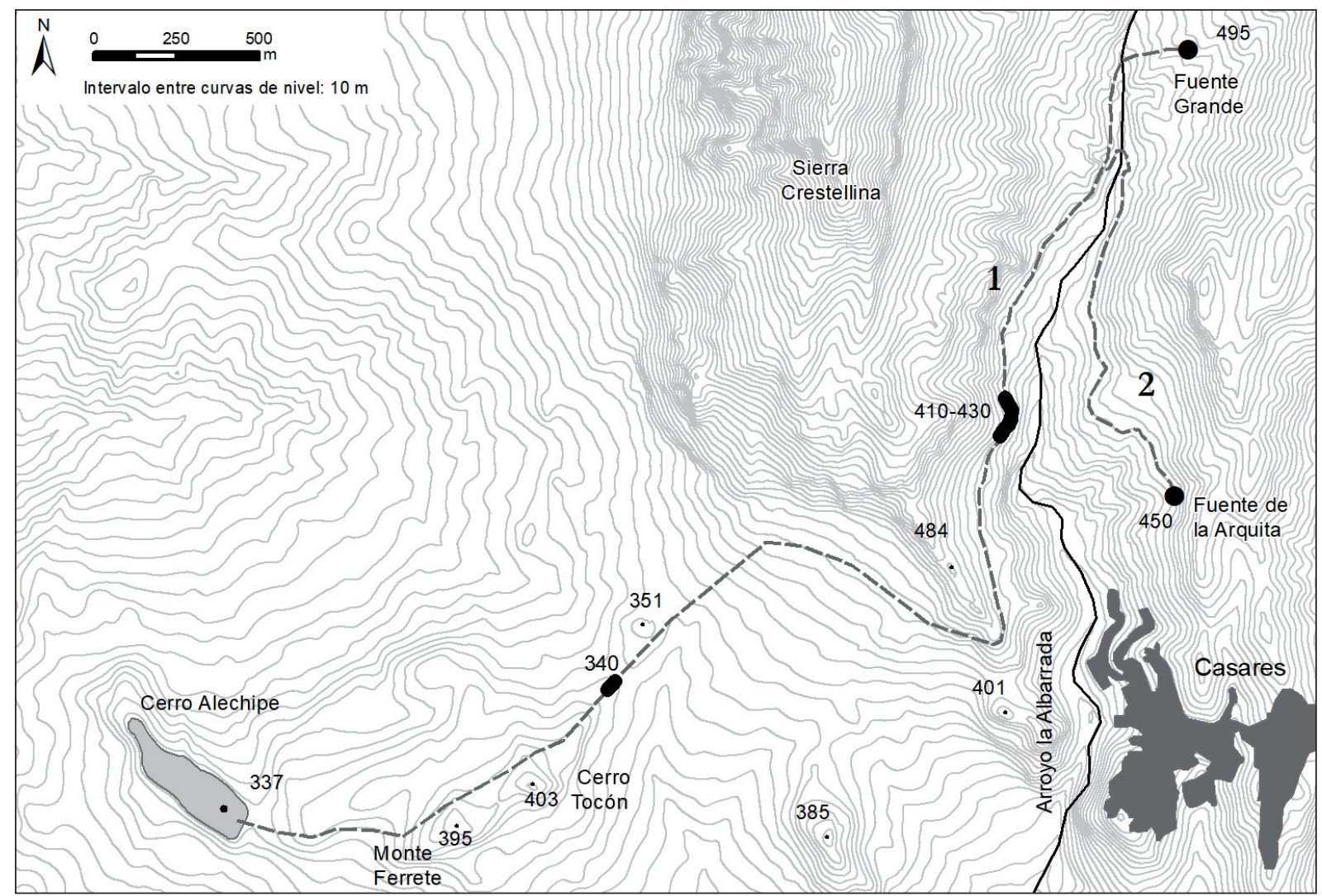

Figura 2. Trazado hipotético del acueducto romano de Lacipo con indicación de los restos localizados.

sierra Aznar (Arcos de la Frontera, Cádiz). Este asentamiento, localizado sobre un cerro, presenta importantes infraestructuras destinadas a la captación, conducción y almacenamiento de agua, pero cuya función no está clara (Guerrero 2001, Gener 2001). En cambio, el yacimiento no parece tratarse de un núcleo urbano, sino más bien de algún tipo de explotación de carácter minero o industrial (Mata et al. 2010).

Tras estos vestigios no detectamos más huellas de la conducción hasta llegar al llano. Suponemos que continúa alternando diversas soluciones constructivas adaptándose al relieve y a la pendiente por la ladera sureste de la sierra Crestellina, hasta su extremo sur. De forma gradual va descendiendo y bordeando la sierra para dirigirse al cerro Alechipe, donde se asienta la ciudad. En este recorrido, el acueducto debe discurrir entre las cotas 420 y $410 \mathrm{~m}$ s.n.m., bordeando la montaña en su punto más bajo.

Posteriormente, la conducción avanza por un terreno menos accidentado, a través de una sucesión de cerros de alturas suaves. Esta transición de la zona montañosa a la llanura conlleva un problema. Los constructores romanos debieron emplear alguna solución constructiva que permitiera el descenso drástico del nivel de cota. Una alternativa podrían haber sido los pozos de resalto o estructuras que permiten el frenado de la fuerza del agua, la ruptura de la pendiente y los cambios de dirección (Chanson 2000). Es una técnica utilizada en otros lugares con características similares, como en Córdoba. El acueducto romano de Valdepuentes o Aqua Vetus debía superar la acusada pendiente de Sierra Morena para alcanzar el llano. Para ello emplearon casi una cuarentena de pozos de resalto o spiramina, en los cuales el agua llenaba la parte más profunda y, una vez frenada la fuerza de la caída, salía remansada por otro canal a $5 \mathrm{~m}$ de profundidad respecto al primero. En algunos casos, el canal sucesivo se situaba en ángulo de $90^{\circ}$ respecto al siguiente, permitiendo la variación del trazado (Ventura 1996: 30-40, Ventura y Pizarro 2010: 190-191). Esta técnica también la encontramos en otros acueductos béticos, como en los de Baelo Claudia (Bolonia, Cádiz), donde los pozos ayudan a reducir la velocidad adquirida por el agua como consecuencia de una fuerte pendiente media (Jiménez 1973: 277, Sillières 1997: 145, Borau 2015: 155 y 157) 


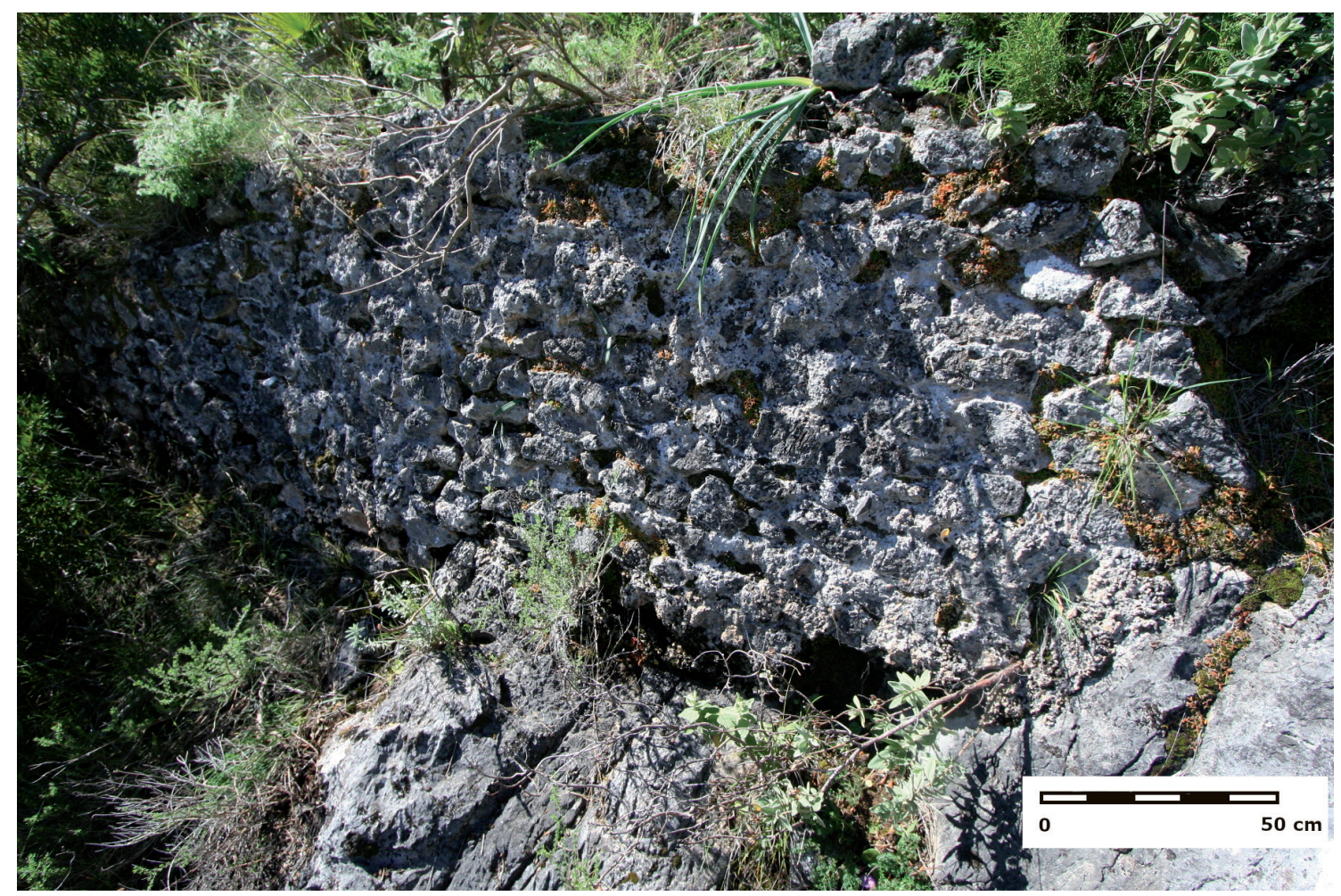

Figura 3. Substructio del acueducto en la ribera derecha del arroyo la Albarrada.

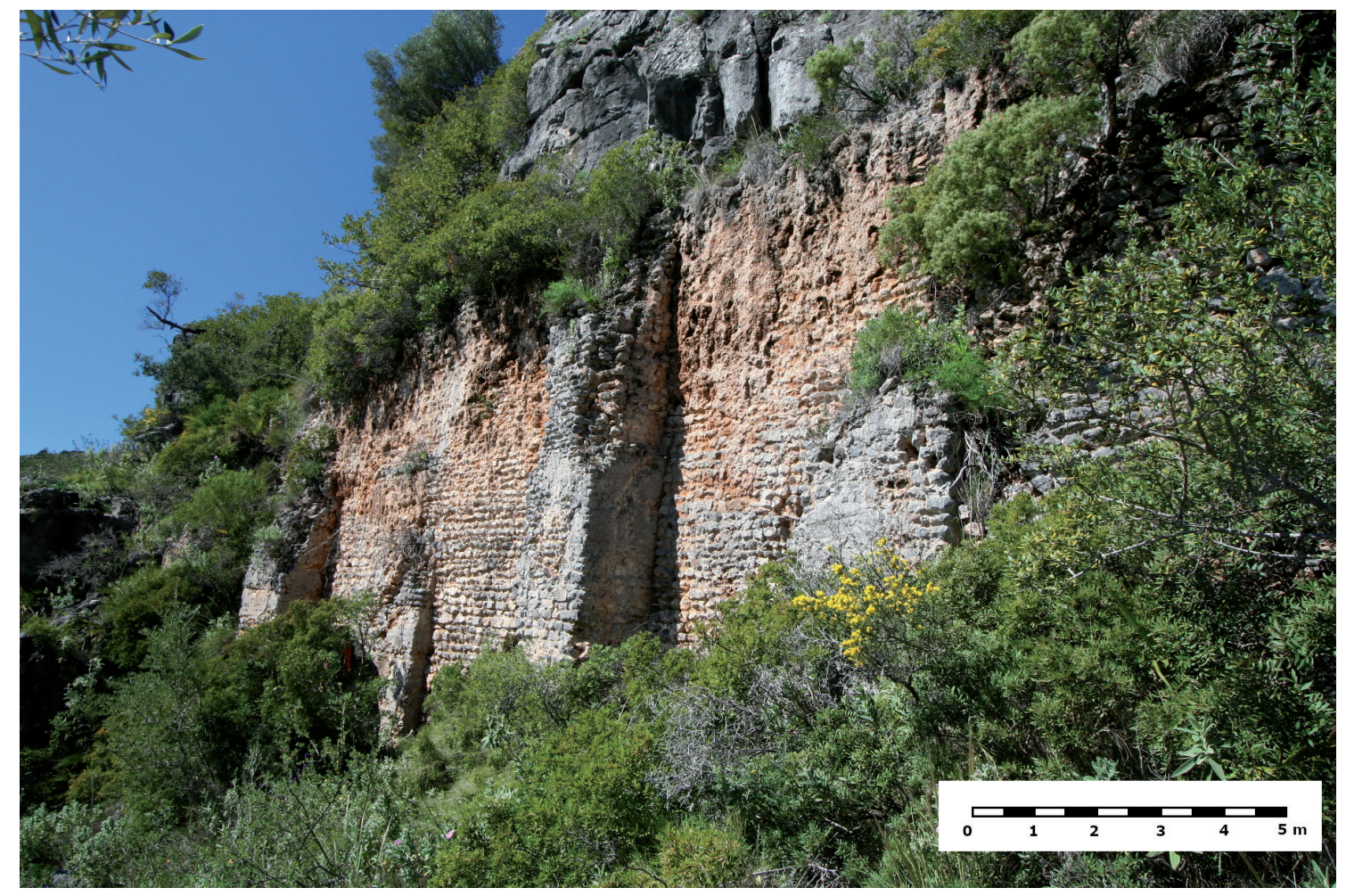

Figura 4. Paredón de sillarejo con contrafuertes para el sustento del specus adosado a la ladera. 


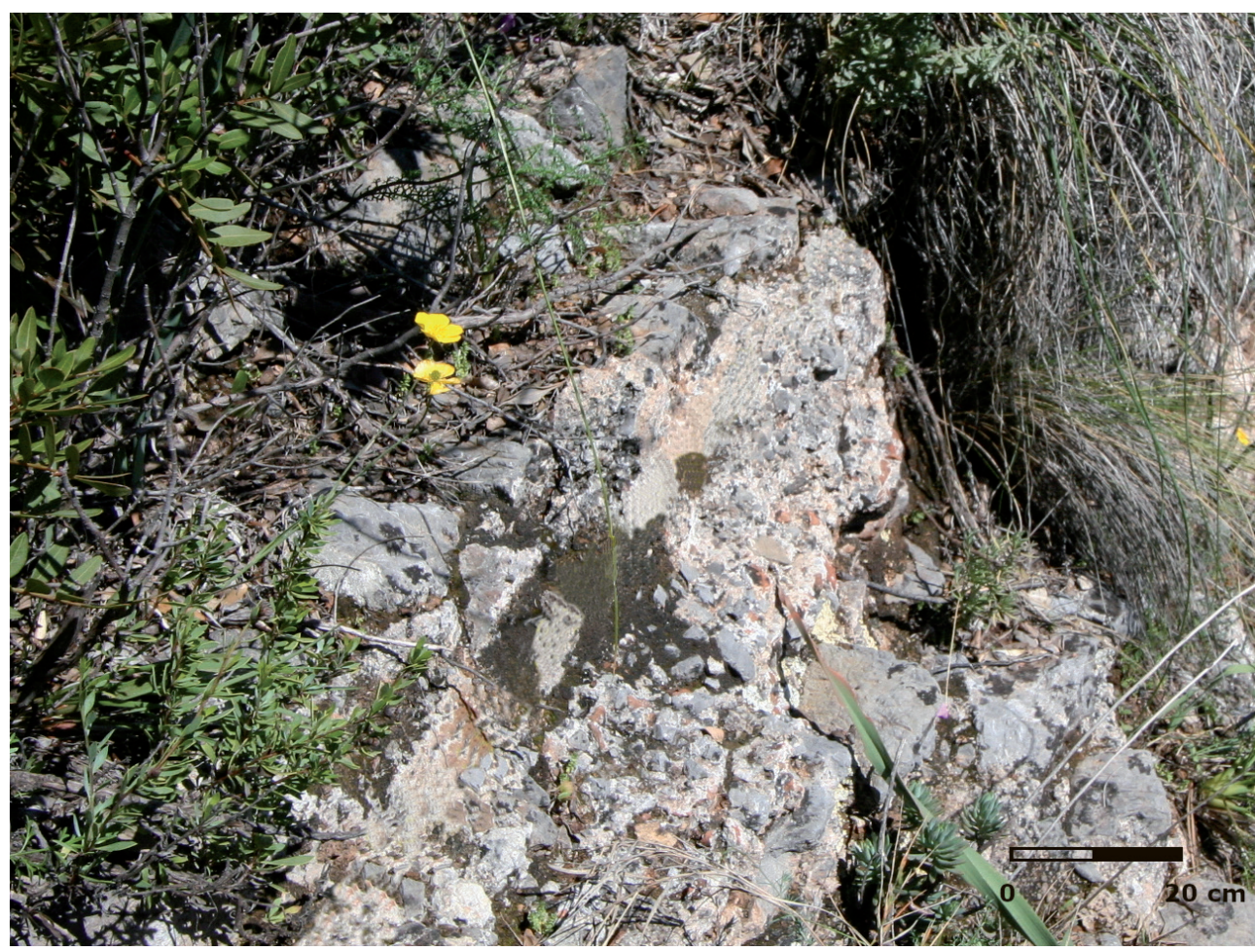

Figura 5. Restos de specus del acueducto.

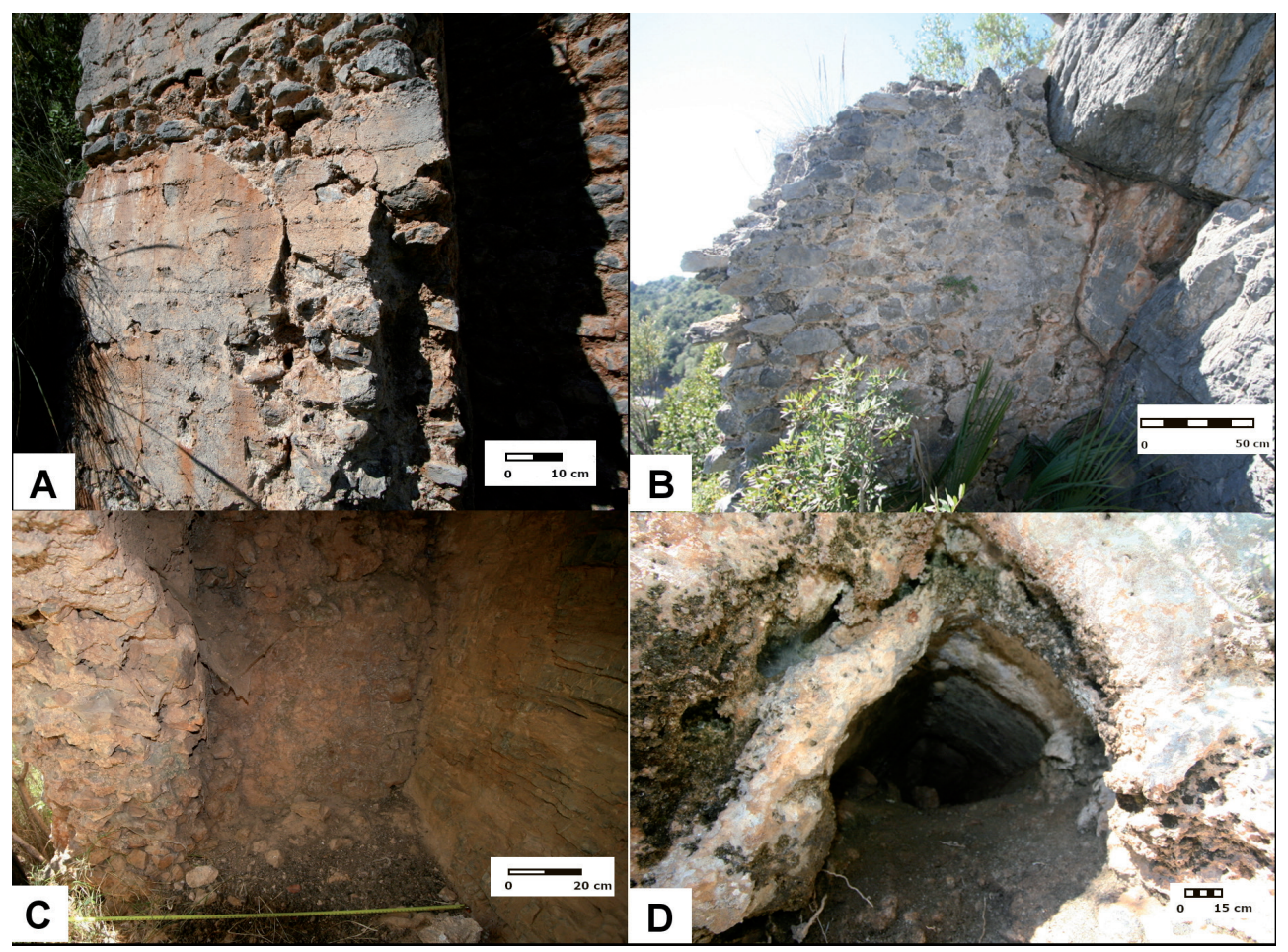

Figura 6. Detalles constructivos del acueducto. A. Enlucido exterior alisado a modo de revestimiento final en el muro de contención. B. Adosamiento del muro de contención a las rocas calizas de la ladera. C. Fractura en el muro de sillarejos que permite observar el adosamiento a la pared de la ladera. D. Aliviadero. 


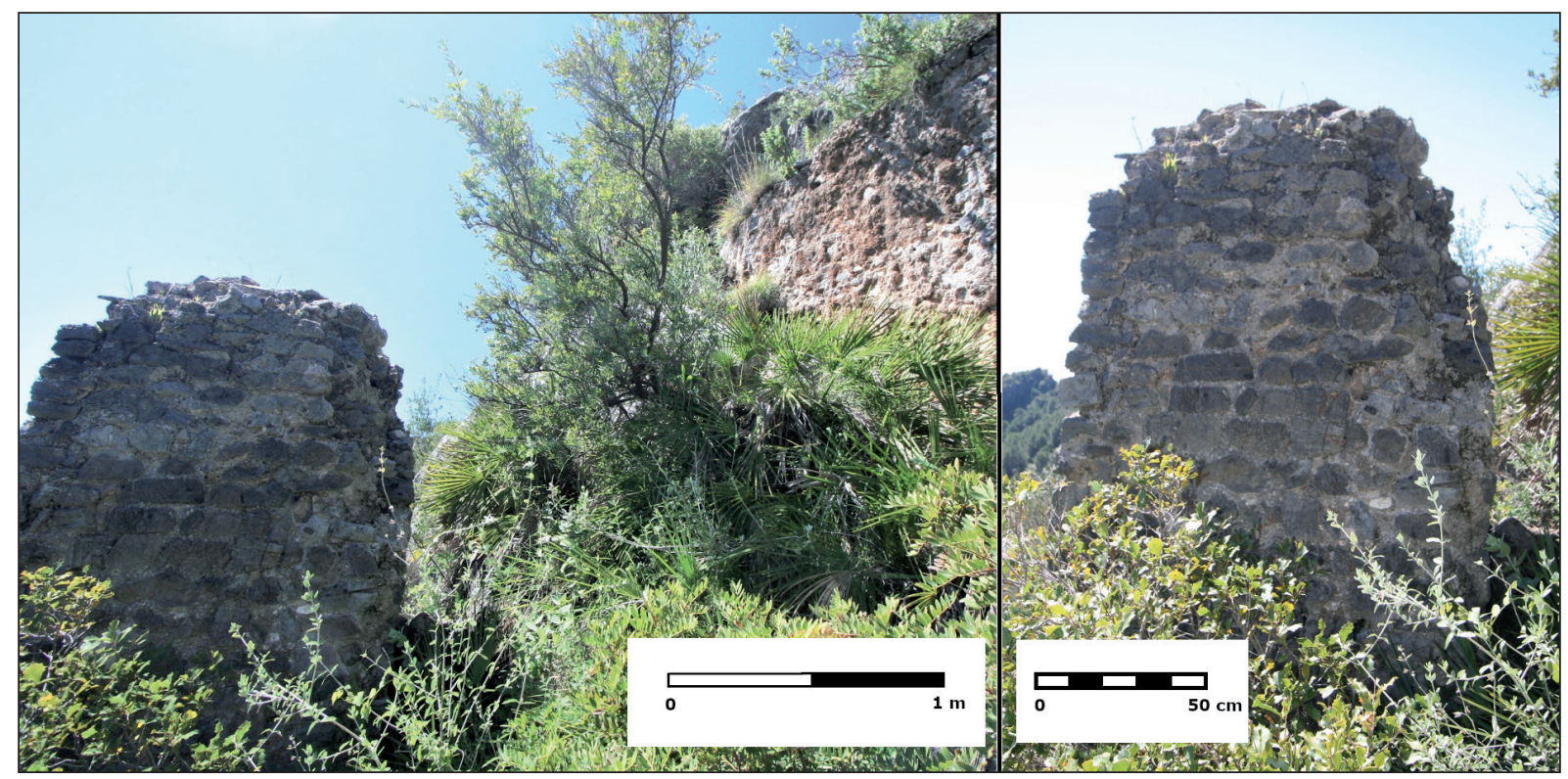

Figura 7. Izquierda: Pilar exento del acueducto en relación al muro de contención de la ladera. Derecha: Detalle del pilar.

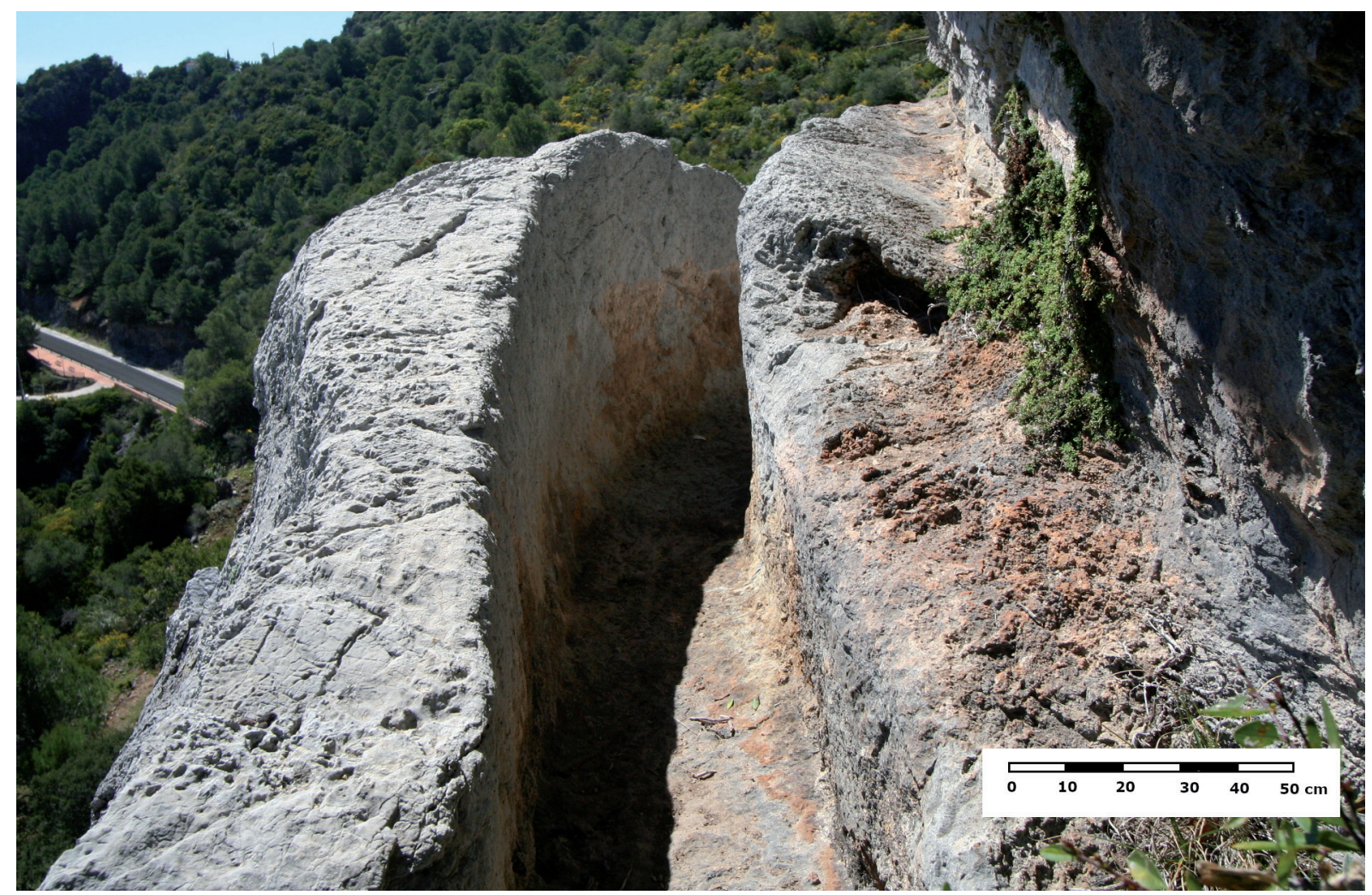

Figura 8. Specus tallado en la roca. 


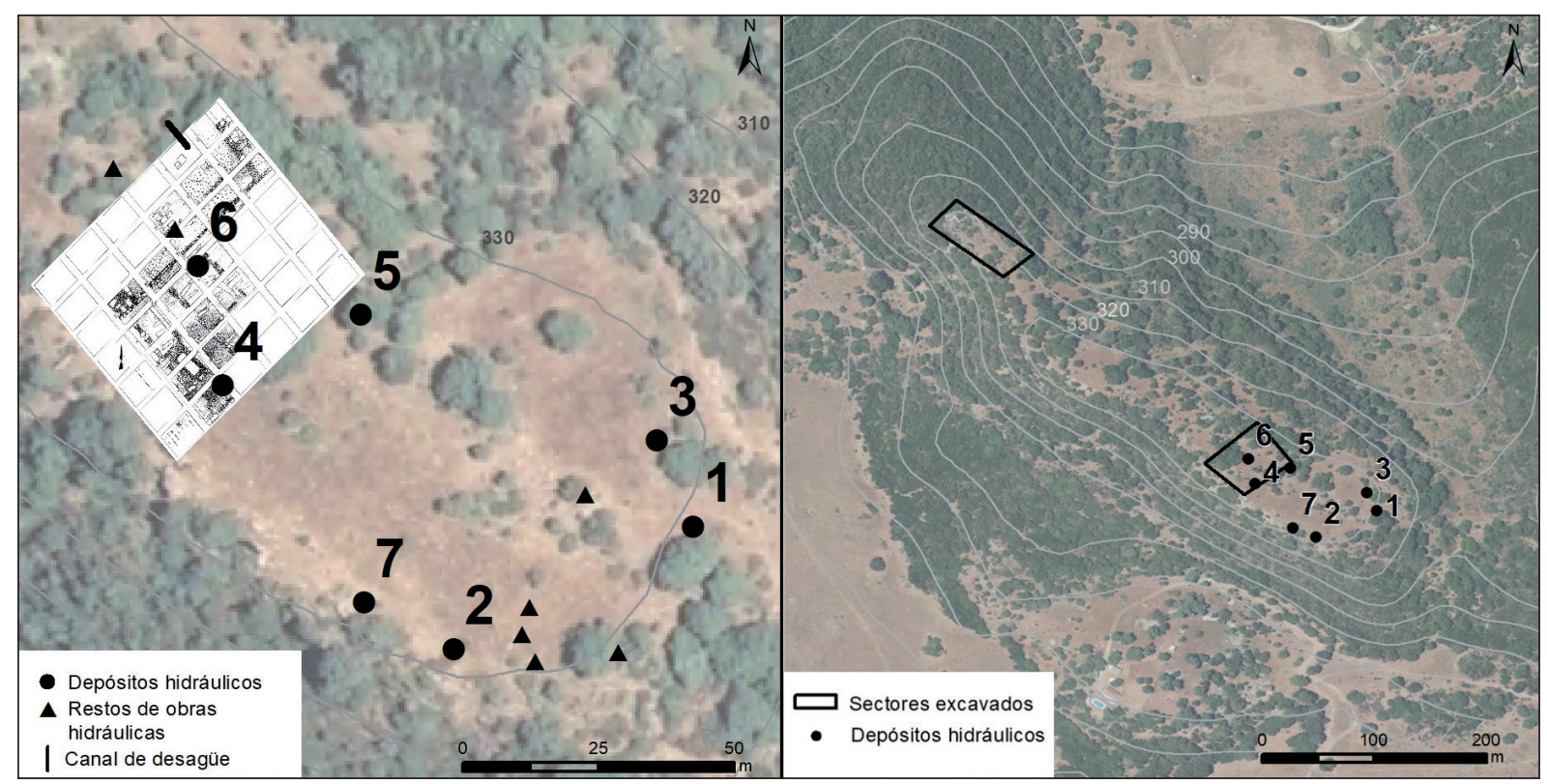

Figura 9. Izquierda: Ubicación de los depósitos hidráulicos documentados en cerro Alechipe. Derecha: Detalle del sector de concentración de los vestigios hidráulicos con la georreferenciación de la planta de la excavación realizada por Puertas (1982) en el sector sur.

Una vez que deja atrás Crestellina, una de las soluciones que emplea para atravesar la llanura y sus suaves cerros es mantener la altura del specus sobre pilares o arcuationes. Unas bases de pilares fueron localizadas al pie del cerro Tocón, en dirección este-oeste, a 340 m s.n.m. Los pilares están realizados en mampostería, coincidiendo con la misma fábrica que los detectados en la ladera de la sierra. Su función sería sustentar el specus, que probablemente fuese de mampostería. La altura del pilar nivelaría la diferencia de cota desde su procedencia, desde el final de la ladera de la sierra. El cerro Tocón alcanza los $400 \mathrm{~m}$ s.n.m., por lo que debería bordearlo entre las cotas 340 y 350 en su lado izquierdo o derecho, al igual que ocurre con el monte Ferrete, situado a continuación. Tras salvar ambas elevaciones, el acueducto debe discurrir por el llano que limita los cerros y el Alechipe, a una cota de $311 \mathrm{~m}$ s.n.m. En este último tramo el acueducto emplearía la técnica de specus sobre arcuationes, siendo los pilares las bases de los mismos. Esta técnica fue muy utilizada en la construcción de acueductos en el mundo romano (Hodge 1992: 129-147). De la misma contamos con numerosos ejemplos en Hispania (Sánchez y Martínez 2016: 50-52).

Finalmente, sobre pilares o sobre substructio, la canalización alcanzaría la cota de 328-330 m s.n.m., accediendo por la ladera sureste del cerro Alechipe. En el final de la ladera, en su sentido ascendente, hemos detectado restos de un murete a modo de substructio que podría pertenecer a la conducción. Además, la concentración de depósitos hidráulicos en esta parte del cerro induce a pensar en una entrada del acueducto por esta vertiente, como ya apuntó Soto Jiménez (1979: 6-7). No podemos asegurar qué cisterna es la que recoge las aguas de la conducción a su llegada, a modo de castellum aquae, ya que no encontramos vestigios de su conexión. El depósito debería encontrarse en la cota más alta del cerro, para posteriormente proceder a la distribución del agua por gravedad.

La longitud que discurre entre la fuente de captación y las construcciones hidráulicas del yacimiento es de 3,7 km en línea recta. En cambio la conducción, en su adaptación al terreno y ante la necesidad de mantener la cota, alcanzaría los $5 \mathrm{~km}$, teniendo en cuenta el obstáculo que supone la estribación sur de la sierra Crestellina.

\section{EL ABASTECIMIENTO DE AGUA: EL AGUA EN LA CIUDAD, LOS DEPÓSITOS HIDRÁULICOS Y LAS CISTERNAE}

Una serie de depósitos hidráulicos y cisternas constituyen los vestigios más llamativos del yacimiento. 
Los encontramos concentrados en la parte sur, suroeste y sureste del cerro Alechipe. Esta agrupación se sitúa en el posible punto de acceso del acueducto a la ciudad. El terreno donde se asientan está aterrazado, para así aliviar la pendiente de la zona alta del cerro. Las construcciones de la parte más baja se sitúan en torno a los 328 m s.n.m., mientras que aquellas emplazadas en la parte más alta, lo hacen sobre una cota de 337 m s.n.m.

Los depósitos han sido documentados en las visitas arqueológicas realizadas al yacimiento, a excepción del número 6, que fue localizado en las excavaciones practicadas en el año 1975 (Puertas 1982) y que no es visible en la actualidad.

- Depósito 1: Se encuentra en el borde de la planicie del cerro sobre la que se extiende el yacimiento, en la ladera sureste. Está situado en la cota más baja con respecto a las siguientes construcciones, a 329 m s.n.m. El depósito se encuentra exento, sin estar relacionado con otra estructura ni integrado en ella. El estado de conservación no es bueno, pues está fracturado por la mitad, quedando una de sus partes desplazada hacia la ladera. La planta es rectangular, con dos cámaras abovedadas comunicadas por medio de un arco de medio punto. Presenta restos de cubierta abovedada. Su orientación es oeste-este y sus dimensiones aproximadas, teniendo en cuenta el desplazamiento y fractura, son 3,5 m de largo y $2,88 \mathrm{~m}$ de ancho. La altura hasta la cubierta es de 2,32 $\mathrm{m}$, siendo 1,71 $\mathrm{m}$ hasta el arranque de la bóveda y $0,55 \mathrm{~m}$ el arco, con una altura total de 2,26 m. El grosor de los muros es 0,60 m. Su cubicaje aproximado calculado a partir de estas medidas es $22,78 \mathrm{~m}^{3}$. Está construido en sillarejo, compuesto por piedras de pequeño tamaño trabadas con mortero de cal. El arco de comunicación entre las dos cámaras está reforzado con ladrillos. Posee revestimiento en opus signinum con varias capas, presentando una final más lisa preparada a modo de superficie. También podría ser fruto de una obra posterior de restauración. Las esquinas se hacen cóncavas, otorgando una forma ovalada a los bordes con el propio signinum para asegurar la estanqueidad en las juntas, aprovechando el revoco que aporta el mortero. No sabemos si el fondo estaría dispuesto a dos niveles con el objeto de depurar las aguas o decantarlas, tal y como aconseja Vitrubio (8.6.15.). El desplazamiento de parte del depósito hacia la ladera nos impidió conocer el nivel de cota. Los orificios de entrada y salida del agua no pudieron ser detectados.
- Depósito 2: Corresponde a los restos de una gran estructura abovedada de la que solo se conserva una parte, con unas dimensiones de al menos $2 \mathrm{~m}$ de ancho. Ocupa uno de los laterales de la parte suroeste del cerro, situado junto a los restos de la muralla que lo circunda. Se emplaza en una cota más alta que el anterior depósito, a 331 m s.n.m. Conserva el arranque y parte de la bóveda de cañón que poseía a modo de cubierta. No conocemos si disponía de una sola cámara o dos. La estructura presenta unos potentes muros realizados en sillarejo, aunque con piedras de mayor tamaño que la anterior construcción. Igualmente está revestido en opus signinum, con el detalle de un cordón hidráulico en las juntas. Puede existir relación con los restos de una substructio de sillarejo, argamasa y signinum a modo de canal, que se localiza en la parte final de la ladera del cerro y apunta en dirección a este depósito. Esta posible conducción podría pertenecer a parte del acueducto. Por otro lado, entre el reservorio y la substructio encontramos restos de lo que podría haber sido un pequeño lacus, o la pavimentación de una fuente ornamental de modesto tamaño de algún edificio.

- Depósito 3: La siguiente estructura se sitúa en la parte este del cerro, en el lado contrario al depósito 2. El estado de conservación es malo, ya que mantiene solo uno de sus ángulos, que parece corresponder con el fondo. La orientación es oeste-este, dirigiéndose hacia el lugar donde se dispondría la parte habitacional del yacimiento. Situado entre la cota 328 y 331 m s.n.m., constituye otro depósito de tamaño considerable, presentando una longitud conservada de al menos $3,5 \mathrm{~m}$. En sus proximidades se encuentran restos de lo que sería su cubierta, abovedada. La técnica constructiva es muy parecida a la empleada en el depósito 2. Gruesos muros están realizados en sillarejo trabado con mortero, formado por piedras de mayor tamaño que el primer depósito. La capa de revestimiento en signinum está formada por fragmentos cerámicos de gran tamaño, aportándole un color ocre muy marcado. Está en correlación y en la misma dirección que otros vestigios de estructuras hidráulicas. Estos restos se encuentran en una altura un poco más elevada, entre los 332 y 333 m s.n.m., y se corresponden con aparentes depósitos, atanores y fragmentos de signinum.

- Depósito 4: Esta construcción hidráulica fue hallada en la campaña de excavación del año 1975, en el extremo sur del cerro (Puertas 1982: 25 y 32-33). 


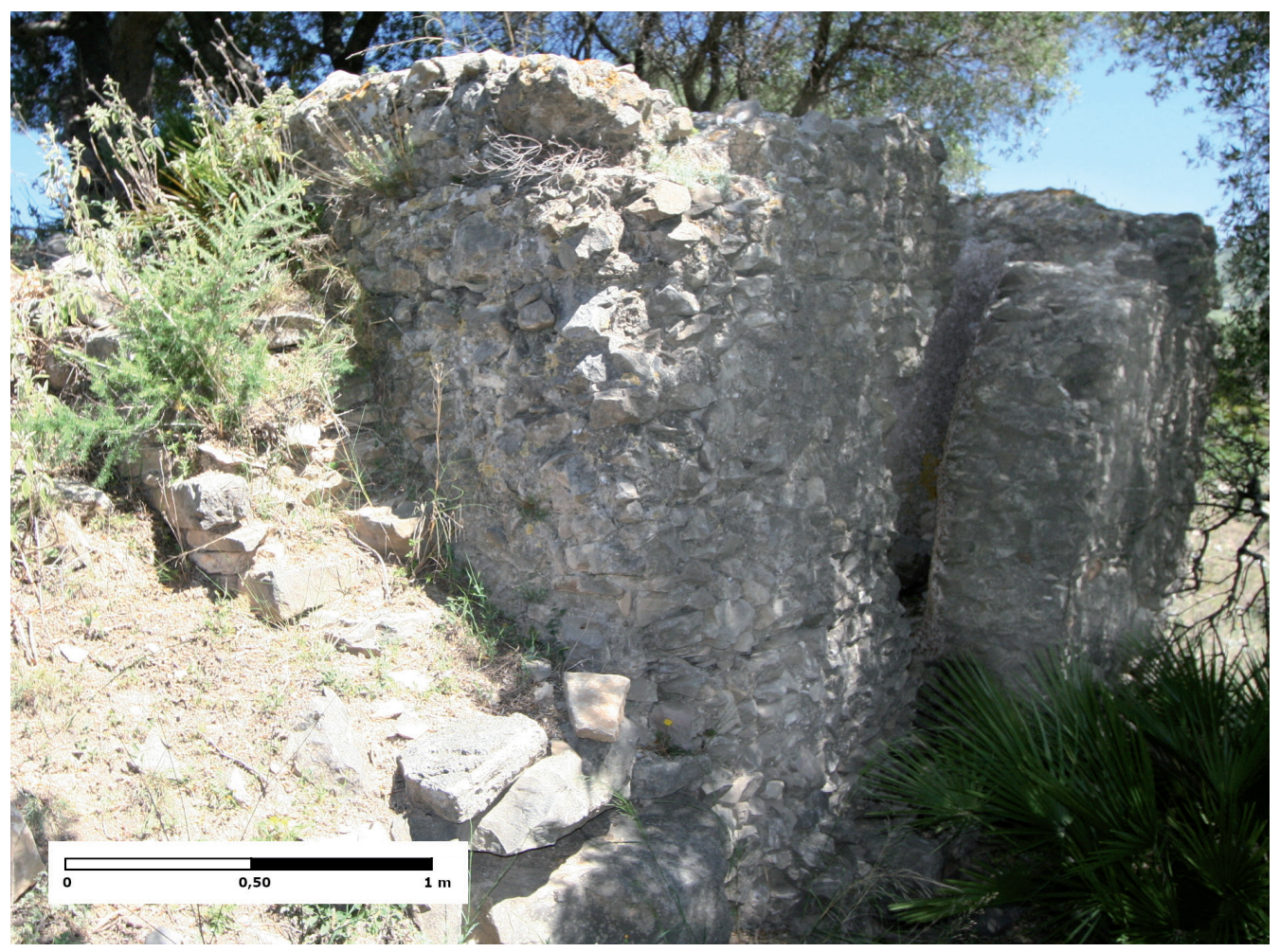

Figura 10. Exterior del depósito hidráulico 1.

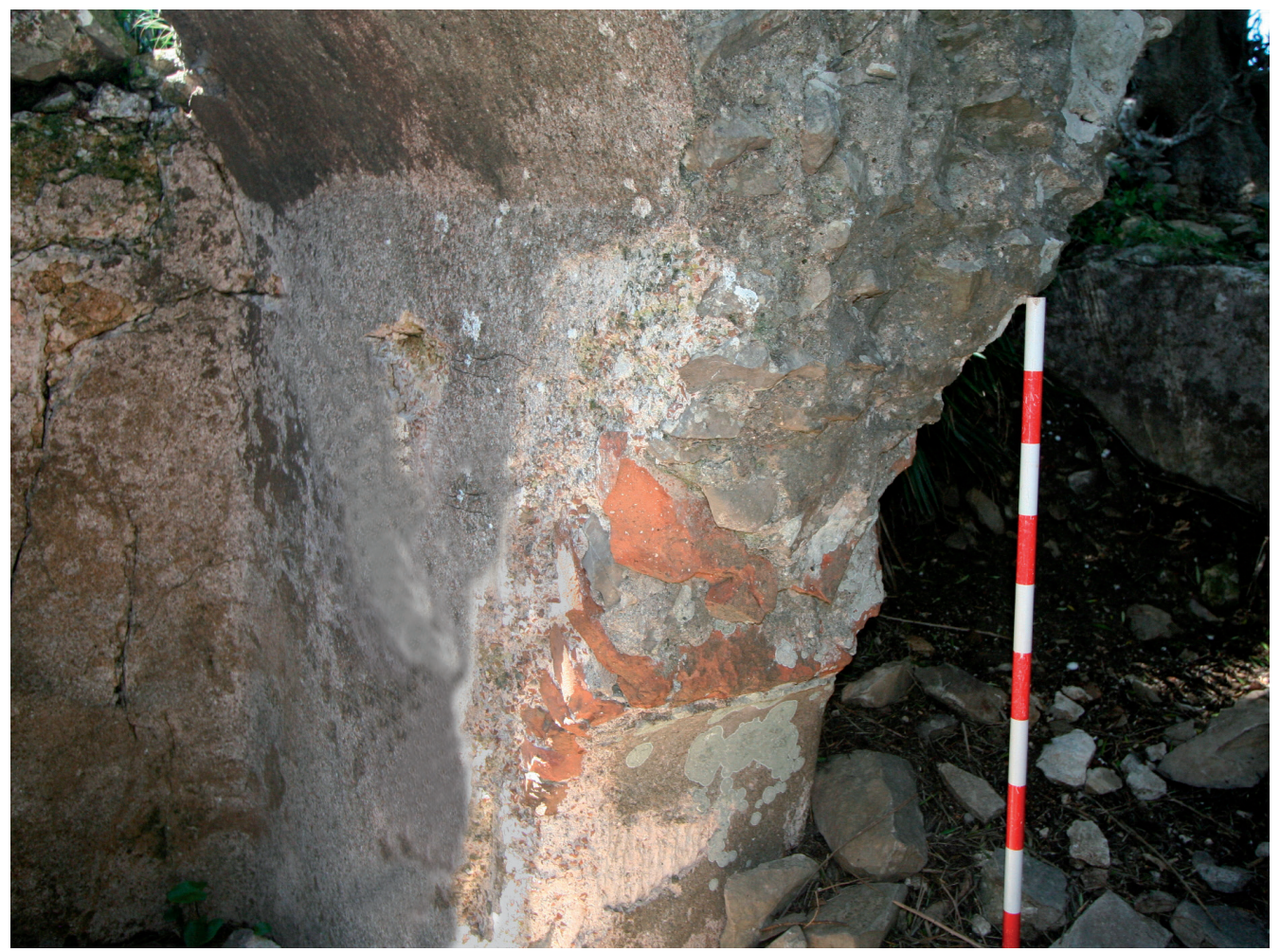

Figura 11. Detalle del arco de comunicación de las dos cámaras del depósito hidráulico 1.

ISSN: 1133-4525 ISSN-e: 2255-3924 
Está asociada a una de las estructuras documentadas en el nivel cronológico romano, interpretada como gran edificio público. Se encuentra sobre la cota de 337,5 m s.n.m. En la actualidad continúa siendo visible, lo que nos permitió documentarla. La planta del aljibe es rectangular y sus extremos redondeados. Está excavado en el subsuelo y sus lados reforzados con sillarejos previamente labrados, redondeados en las esquinas. Finalmente se impermeabiliza con mortero hidráulico u opus signinum. En función de sus características morfológicas podemos calificarlo como cisterna a bagnarola. Las dimensiones son 4,7 $\mathrm{m}$ de largo y 2,4 $\mathrm{m}$ de ancho, junto con una profundidad máxima de $2,7 \mathrm{~m}$. La pared oeste y el fondo presentan una marcada curvatura debido al empuje de la tierra.

De su técnica constructiva podemos señalar el uso de dos aparejos diferentes a la hora de revestir los muros. Por una parte se utilizan lajas de piedra escuadradas en los laterales, mientras que por otra se emplea sillería caliza y arenisca labrada en redondo en los ángulos. Localizamos dos lugares por donde se produciría la entrada de los tubuli cerámicos que conducen el agua hacia ella. Además, en la excavación se registraron canalillos que llegaban al compartimento donde se localiza la cisterna (Puertas 1982: 25). El signinum del revestimiento parece diferir en composición al de los demás depósitos, siendo la capa más fina. De la cubierta no tenemos constancia. Según la tipología del aljibe, su relación con el nivel de suelo y las estructuras murarias asociadas, dispondría de una cubierta adintelada, con una abertura a modo de brocal para la extracción del agua, todo ello integrado en una estancia del edificio (Puertas 1982: 34). Como consecuencia del abandono, en la excavación, el interior se encontró colmatado por material constructivo, cerámico y metálico.

- Depósito 5: Se corresponde con restos ubicados en el extremo de la ladera este del cerro. El depósito, de una cámara, está construido siguiendo la misma técnica que los anteriores. Gruesos muros realizados en sillarejo están revestidos en su interior con signinum, con signos de haber sido reparado en diversas ocasiones. No pudimos tomar medidas de la estructura ya que el interior se encontraba colmatado con grandes piedras.

- Depósito 6: Hallado en la campaña de excavación de 1975. No ha sido posible localizarlo, por lo que la información aportada está extraída del informe arqueológico (Puertas 1982: 28). Emplazado sobre la cota 337 m s.n.m., se encuentra inserto en un conjunto constructivo y asociado a estructuras murarias. Presenta un brocal formado por piedras en alineación semicircular. El revestimiento de la cisterna es de opus signinum, alisado en su superficie. Una conducción cerámica compuesta por piezas abocinadas ensambladas era su método de alimentación. En su interior se hallaron fragmentos de cerámica y de tejas. La profundidad del aljibe alcanza los $3 \mathrm{~m}$. En la información contenida en la memoria de excavación no se detalla la morfología de su planta, sin embargo, atendiendo a sus características constructivas, su ubicación y su cercanía a la anterior cisterna documentada, podría tratarse de otra cisterna a bagnarola.

- Depósito 7: Encontramos vestigios de otro depósito hidráulico en la vertiente oeste del cerro. Está emplazado a 332 m s.n.m., en el inicio de la ladera, cerca de los restos interpretados como muralla. Emplea la misma técnica constructiva que los reservorios de grandes dimensiones. Al estar desprendido en una pendiente escarpada y oculto por densa vegetación, no pudimos documentar más detalles constructivos.

En cuanto a la función de los depósitos hidráulicos presentes en Lacipo, a partir de los datos con los que contamos planteamos algunas ideas de cómo se integran en el ciclo del agua de la ciudad.

En una ciudad romana, el ciclo urbano del agua se inicia con la captación y conducción. Posteriormente se distribuye en el interior de la propia urbe y en algunos casos se almacena. El punto de llegada del acueducto al asentamiento generalmente se corresponde con un depósito o castellum aquae. Esta construcción sirve o únicamente para distribuir el agua, tal y como indica de manera teórica e ideal Vitrubio (8.6.), o para distribuirla y almacenarla (Peleg 2000, Wilson 2001, Bukowieki et al. 2008). Otra de sus funciones principales es la decantación y eliminación de las impurezas de las aguas portadas por el acueducto (Bukowieki et al. 2008). Asimismo, estos castella pueden ser de grandes dimensiones, como el gran depósito de Italica (Santiponce, Sevilla) (Pellicer 1982) y el documentado en Sevilla (García García 2007), o ser más modestos, como el presente en Baelo Claudia (Borau 2015: 162-164).

En el caso de Lacipo, la relación de alguno de estos depósitos con el acueducto parece clara. El aqua ducta alcanzaría la ciudad por la ladera sureste del cerro, siendo el punto de más fácil acceso y donde 


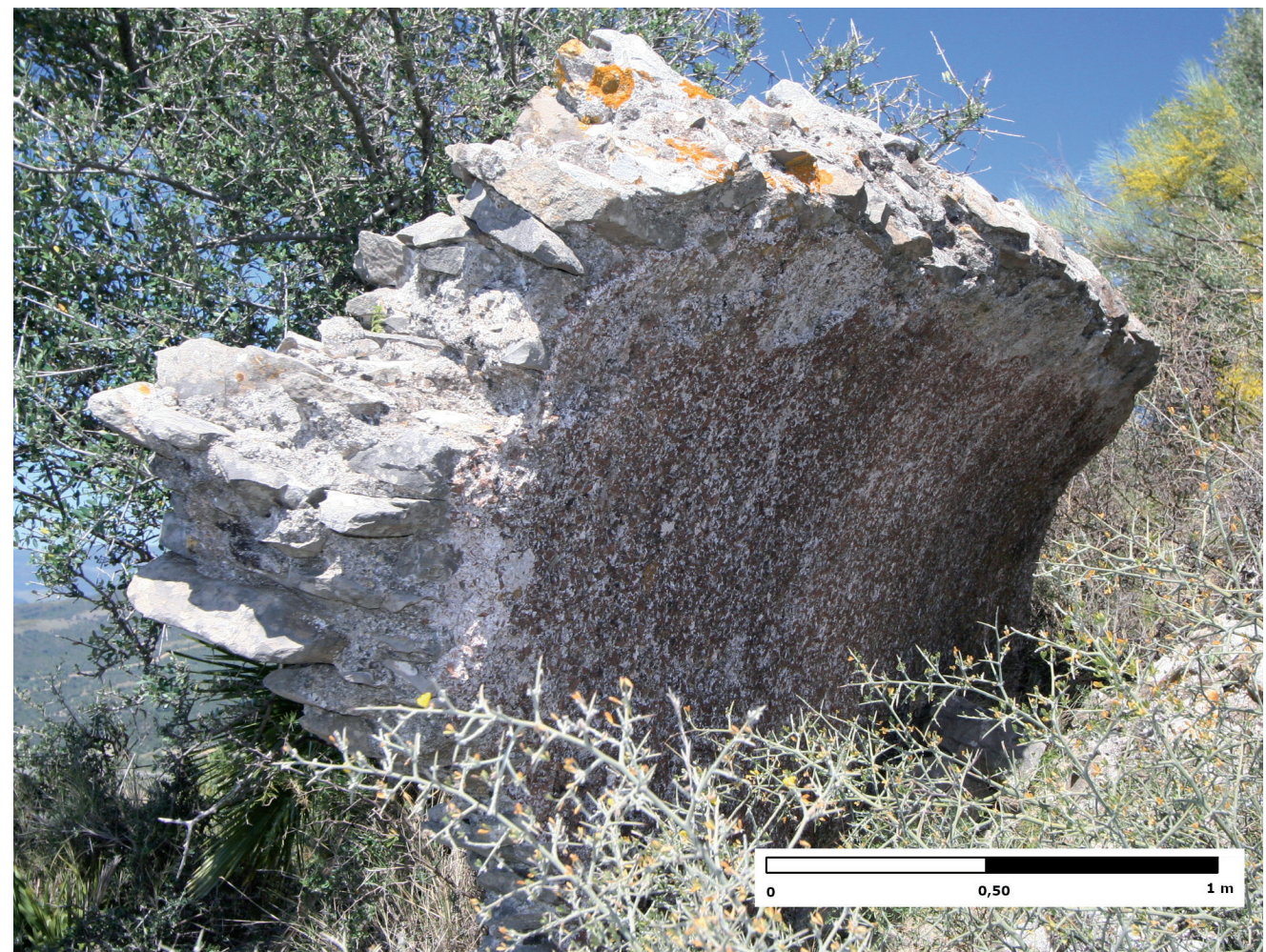

Figura 12. Restos conservados del depósito hidráulico 2.

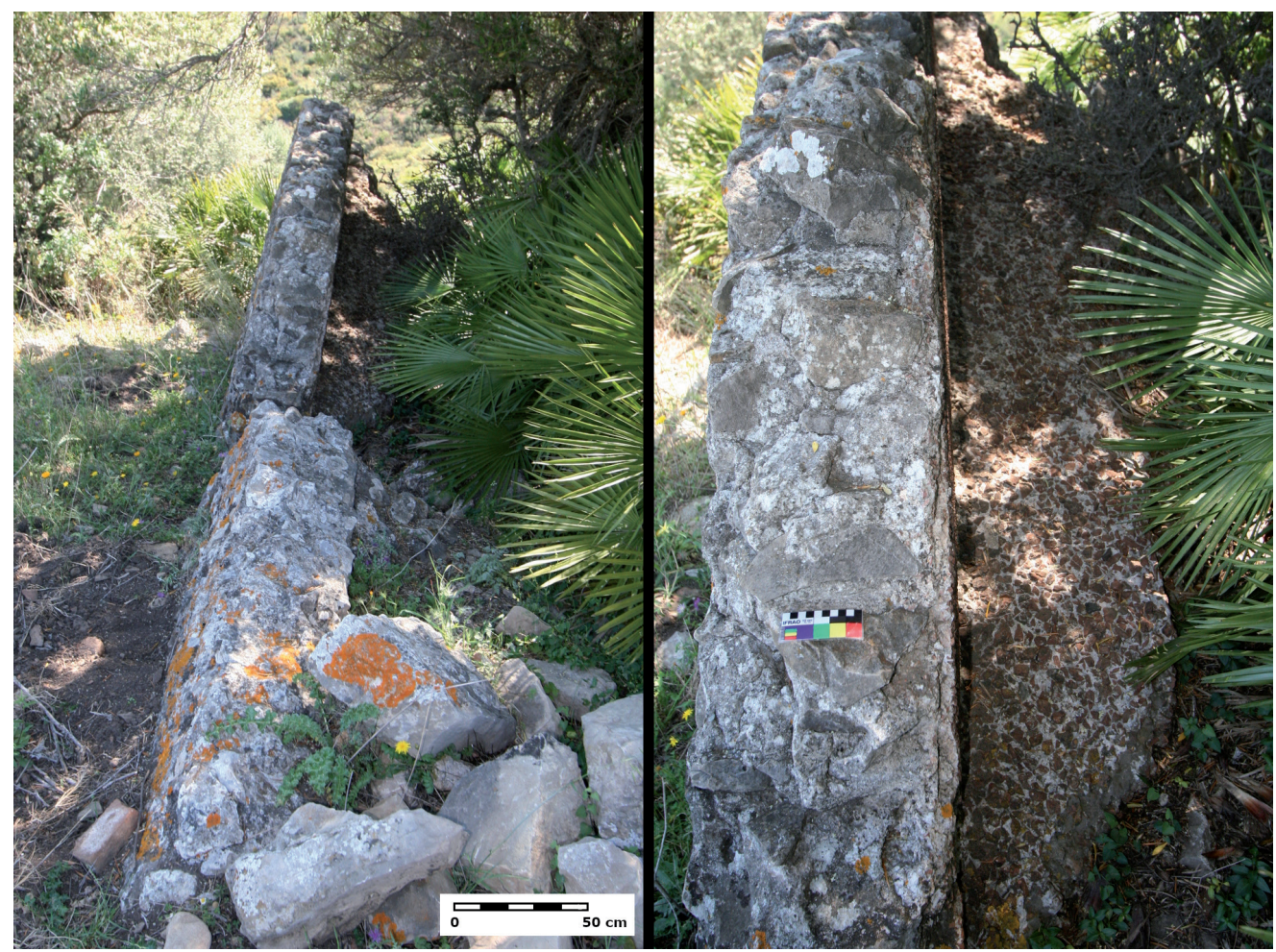

Figura 13. Restos conservados del depósito hidráulico 3.

ISSN: $1133-4525$ ISSN-e: 2255-3924

SPAL 29.1 (2020): 189-212

http://dx.doi.org/10.12795/spal.2020.i29.07 


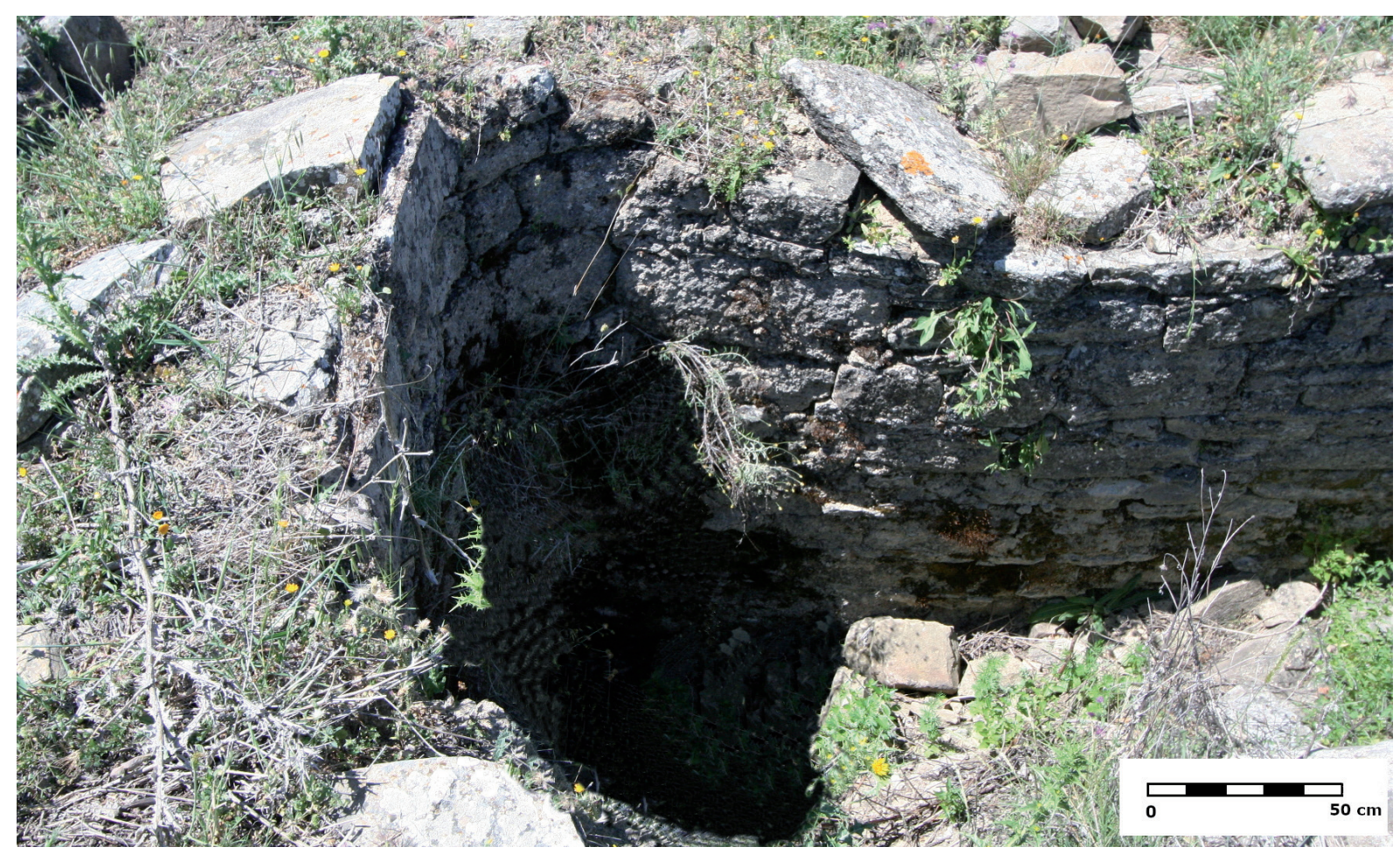

Figura 14. Uno de los extremos del depósito hidráulico 4 o cisterna a bagnarola.

probablemente se situara la puerta principal. Los reservorios de grandes dimensiones documentados se emplazan en esta parte. Al igual sucede con otros castella aquae que se ubican en la entrada de las urbes romanas. Uno de los más representativos es el de Pompeya, en la Puerta del Vesubio (Adams y Varène 2008), o el de Ostia en la Puerta Romana (Bukowieki et al. 2008). Por otro lado, los depósitos están exentos aparentemente, sin edificios que sirvan de impluvia para su llenado, sugiriendo una alimentación mediante el agua del acueducto.

Según la topografía de Lacipo, el depósito situado a mayor altura debería ser el castellum aquae del acueducto. Excluimos las dos cisternas a bagnarola que por su situación, insertas en un edificio, y su tipología no son propias de un castellum. Los reservorios situados en las cotas más altas son el depósito 2 y 3 . Del número 2 no conocemos su solución de cubierta, aunque sí sus grandes dimensiones. Al estar fracturado no podemos establecerlas con exactitud, pero al menos posee más de $3 \mathrm{~m}$ de largo. Se encuentra a la misma cota que el depósito 3. Uno y otro están emplazados a ambos lados del límite de la parte amesetada del cerro, donde se asienta la ciudad. Del reservorio 3 solo se conserva el arranque de la bóveda. Sin embargo, la potencia de los muros sugiere que debió disponer de una importante capacidad. Los siguientes depósitos también se encuentran en los límites de la meseta del cerro. En concreto, el número 7 parece desplazado hacia abajo, también fracturado. El depósito 5 es el más cercano a la zona excavada y al edificio de grandes dimensiones documentado.

El modo de conexión entre los depósitos es desconocido. No se conservan restos de tubuli o fistulae en el lugar. Tampoco se ha excavado la zona circundante para localizar canalizaciones. En cambio, sí que detectamos una conducción sobre murete junto al depósito 2 que podría funcionar como canal de conexión. Asimismo, localizamos un atanor en piedra procedente de un conducto que podemos poner en relación con la redistribución interna del agua en el yacimiento.

Las construcciones hidráulicas se distribuyen siguiendo una lógica topográfica, encuadrados entre los 329 y 334 m s.n.m., siempre en los límites de la zona donde se asienta la ciudad. La separación entre las mismas es regular, alternando $50 \mathrm{~m}$ entre las que se encuentran más alejadas, y casi $20 \mathrm{~m}$ aquellas más cercanas entre sí. Por tanto, el agua se concentra en un área determinada del yacimiento. Este detalle puede estar indicando el lugar donde se encontraban los edificios y 


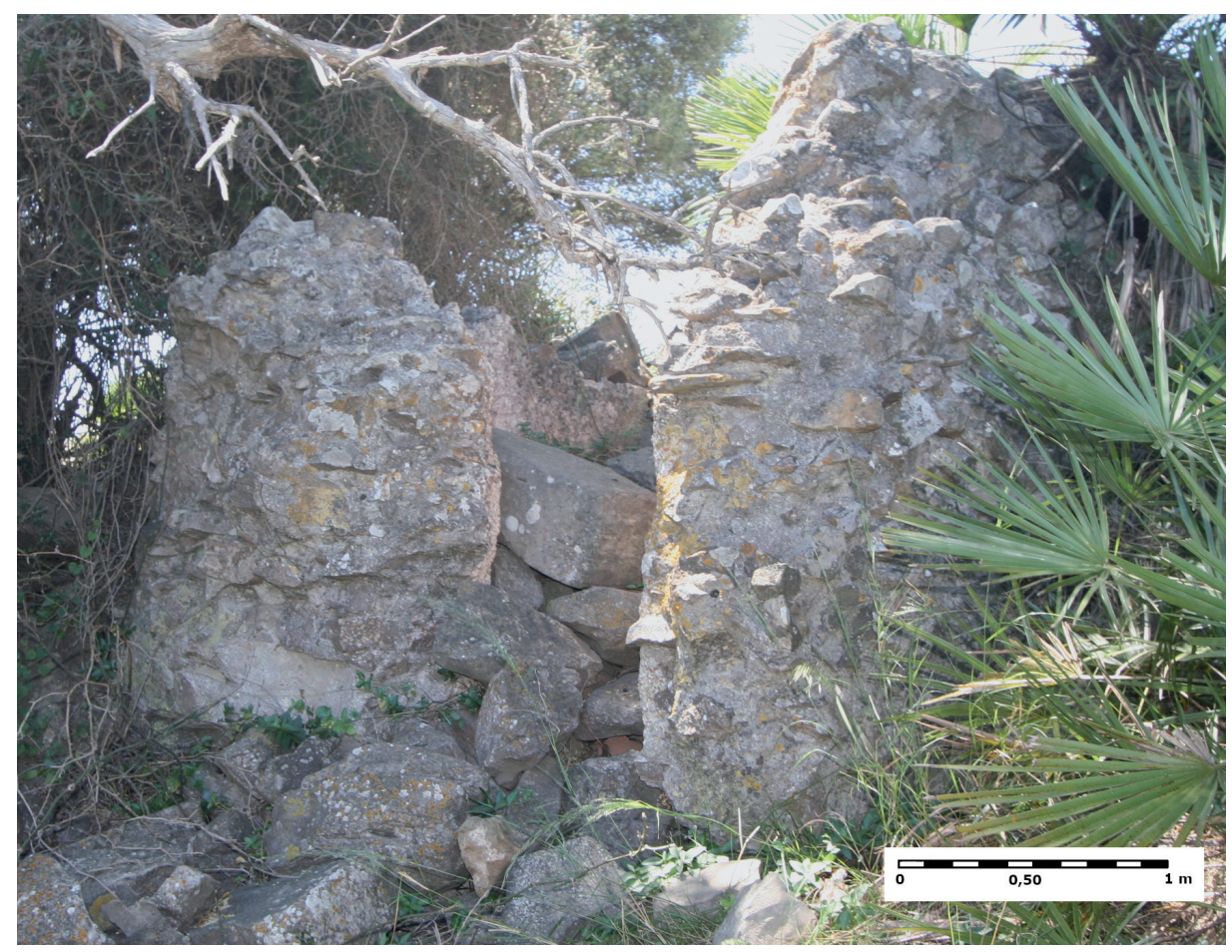

Figura 15. Restos conservados del depósito hidráulico 5.

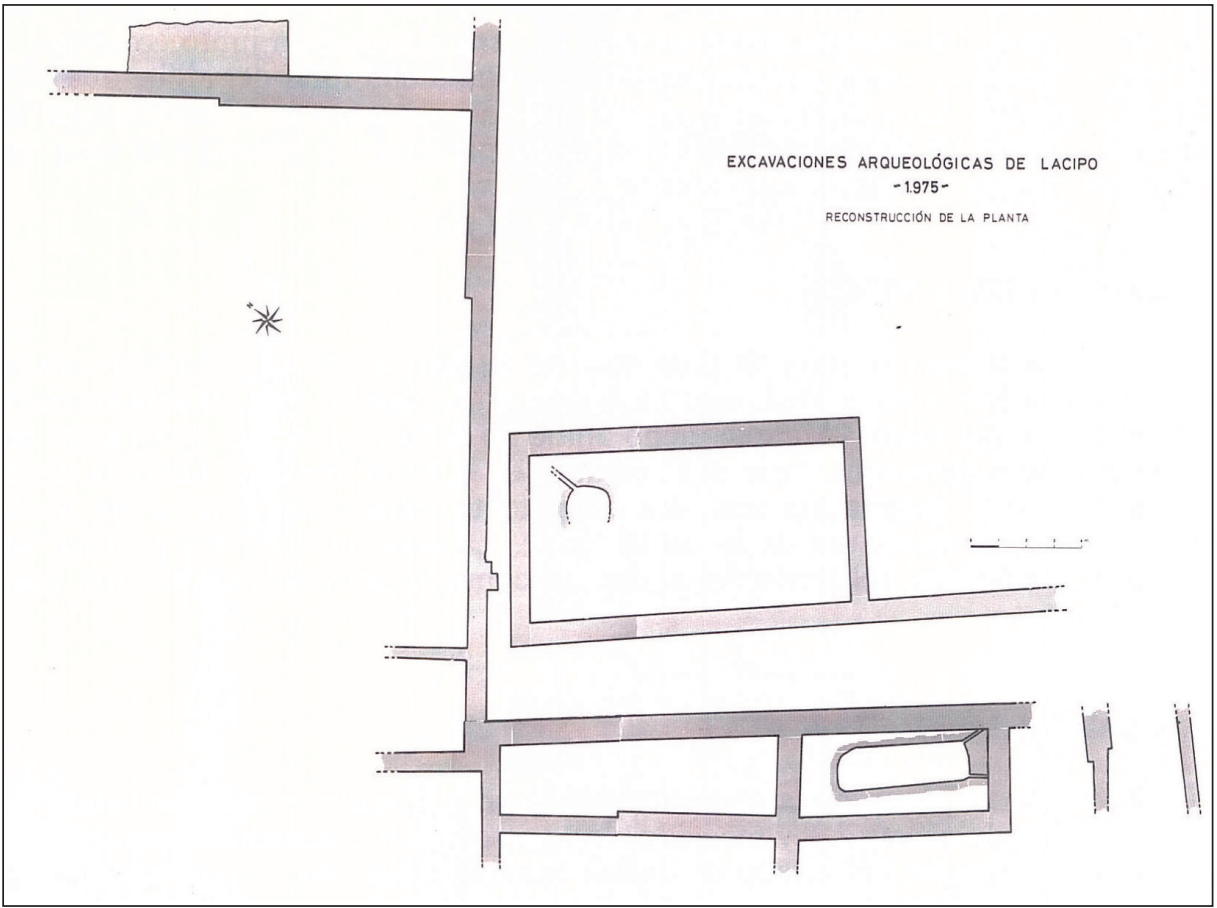

Figura 16. Reconstrucción de la planta del edificio donde se documentan las cisternas halladas en las excavaciones de 1975 (Puertas 1982: 34). 
construcciones a los cuales iba destinada el agua. También podría ser el punto desde donde se distribuía al resto del asentamiento, mediante pequeñas canalizaciones y fistulae.

El yacimiento tiene una extensión aproximada de $45.300 \mathrm{~m}^{2}$, abarcando la totalidad de la zona amesetada del cerro. Una distancia de $450 \mathrm{~m}$ separa los depósitos hidráulicos del espacio más al norte, ocupado por construcciones de carácter defensivo a modo de bastión, sin estructuras habitacionales ni edificios de carácter público (Puertas 1982: 102-105). En cambio, en la parte sur del asentamiento, donde se concentran los reservorios, se documenta un edificio al que por su magnitud y características estructurales, se ha otorgado una función pública (Puertas 1982: 35).

Los testimonios existentes en Hispania de redistribución de agua por medio de cisternae o depósitos hidráulicos los encontramos en la Tarraconensis bien estudiados, concretamente en Bilbilis (Huérmeda, Zaragoza) o Uxama (Osma, Soria). En el municipium Bilbilis, los depósitos están dispuestos en coherencia topográfica para su posterior repartición por gravedad (Martín Bueno 1975). En cambio en Uxama el sistema de alimentación de aguas es más complejo. Al igual que en Bibilis y a diferencia de las presentes en Lacipo, las cisternas están realizadas en caementicium, revestidas con paramento de opus vittatum (García Merino 2006: 185-186). Un gran depósito subterráneo semicircular de decantación era alimentado por un acueducto mediante un artilugio para la elevación de aguas, ya que se encontraban a diferente altura (García Merino 2010: 288-291). Un conjunto de reservorios, casi una veintena, repartidos por toda la superficie urbana de forma escalonada sobre una serie de curvas de nivel, redistribuyen el agua. Se encuentran semiencastrados en las laderas y separados entre sí por distancias regulares. Su capacidad oscila entre los 30 y $40 \mathrm{~m}^{3}$ (García Merino 2006: 185-186, García Merino 2010: 293).

En el presente caso de estudio cabe señalar que dos de los depósitos descritos tienen una tipología y unas características constructivas diferentes. Nos referimos a las dos cisternas a bagnarola que se hallaron en las excavaciones del sector sur (depósitos 4 y 6). Una de ellas se documentó completa. La tipología a bagnarola es de tradición helenística (en la península ibérica: Burés 1998; en el Mediterráneo: Mezzolani 1997, Bonetto et al. 2012). En la provincia Baetica, en la mitad sur occidental, encontramos una concentración de cisternas adscritas a esta tipología. Este fenómeno es consecuencia de la cercanía a las colonias púnicas costeras y de su importancia como influencia cultural en la zona (Bravo 2010). Un ejemplo de ello se encuentra en la cercana $O b a$, actual Jimena de la Frontera (Cádiz). El oppidum guarda con Lacipo una estrecha relación, tanto visual como funcional, debido a su situación en la ribera opuesta del río Guadiaro. Ambos controlan el valle fluvial, que supondría una vía de acceso hacia el interior desde el estrecho de Gibraltar, en su parte más oriental. En esta localidad, durante las excavaciones practicadas en el castillo medieval, se localizó una cisterna a bagnarola asociada a unas estancias de carácter público pertenecientes a la antigua ciudad romana (Tabales et al. 2005: 144). Así pues, encontramos otro aljibe correspondiente a la misma tipología en otra localidad próxima, en la comarca de la Janda, concretamente en Alcalá de los Gazules (Cádiz). Se encuentra asociado a dos grandes depósitos hidráulicos de época romana (Montañés y Montañés 2010).

En función de sus dimensiones, las cisternas $a$ bagnarola laciponenses parecen ser privadas, de uso doméstico. Aunque se encuentren en un edificio de tipo público, podrían cumplir la función de abastecimiento de los usos privados del establecimiento. Por otro lado, el agua destinada a los lacus y fuentes ornamentales, que podrían estar relacionados con los pavimentos de signinum documentados en el edificio (Puertas 1982: 35), sería provista por el acueducto. En la mayor parte de las ciudades romanas, el abastecimiento urbano alterna diversas fuentes de aprovisionamiento: por un lado el aqua ducta, por otro el agua almacenada en cisternas, de procedencia pluvial, y si es posible la captación de las aguas subterráneas mediante pozos (Oleson 2010: 285 ss.). Este sistema se documenta en una de las ciudades donde el abastecimiento hídrico ha sido mejor estudiado. Nos referimos a Pompeya, en la que se ha demostrado que el agua para usos domésticos y cotidianos proviene de las cisternas privadas. Estos aljibes eran domésticos, se encontraban ubicados en el subsuelo de los inmuebles y el agua contenida era recogida mediante impluvia. Por otro lado, el agua proveniente de los acueductos, a la que tienen acceso solo algunos particulares, se emplea para usos ornamentales. Así, el aqua publica es símbolo de poder y ostentación del que la posee, junto con su destinación pública para el embellecimiento y disfrute de la ciudad. Otra de las finalidades del agua corriente es el abastecimiento público mediante lacus o surtidores ubicados en los espacios públicos, de carácter utilitario (Dessales 2008). Existen excepciones a este modelo, lo cual podría demostrar que también se utiliza el agua de los acueductos para aprovisionar cisternas domésticas, 
como parece ser el caso de las cisternas tardías en $\mathrm{Ta}$ rraco (Martínez Jiménez 2012: 35).

\section{PROMOCIÓN Y CRONOLOGÍA DEL CONJUNTO HIDRÁULICO}

El promotor, o promotores, del sistema hidráulico destinado a abastecer a la ciudad nos es desconocido. Hasta el momento no contamos con datos que aporten información sobre su autoría. A ello debemos sumarle el escaso conocimiento existente sobre la propia ciudad y la sociedad que la habitaba. Sin embargo, el registro epigráfico, aunque limitado, menciona a algunos personajes importantes de la civitas. El promotor del complejo hidráulico podría haberse correspondido con un evergeta, una persona adinerada que invierte sus recursos en el beneficio de la comunidad, con el fin de ostentar cargos municipales y adquirir prestigio (sobre el "evergetismo del agua", Corbier 1984: 251, Melchor 1994: 25, Belfaida 2000: 1597). En Hispania contamos con numerosos testimonios epigráficos que rememoran la financiación de obras hidráulicas por parte de particulares (Rodríguez Neila 1988, Mayer 1996).

En este sentido, en Lacipo tenemos constancia de personajes con tal poder que los vemos actuando como promotores de obras y edificios. Uno de ellos es Quinto Fabio Varo, pontífice y quinquevir, que dona un complejo monumental destinado al culto imperial, concretamente una cripta y un hypaetrum ( $A E$ 1981, 504). Asimismo, encontramos libertos ejerciendo cargos relacionados con este mismo culto, como el sevirato, o incluso el flaminato provincial en la capital de la Bética (CIL II 1934, 1935, 1936; CIL II²/7 259). Todos ellos son representantes de un cierto dinamismo económico de la zona, que posiblemente provenga de la exportación de productos del interior hacia los puertos que se sitúan en el ámbito del estrecho de Gibraltar. Además, se ha apuntado una relación de los pobladores de $\mathrm{La}$ cipo con la familia Canuleia, un gentilicio poco común y que debido a la proximidad de Carteia, cuyo deductor fue Lucio Canuleyo, sugiere una relación de sus colonos con Lacipo y su habitantes (Rodríguez Oliva 2006).

Otra posibilidad es la financiación municipal de las obras de infraestructura hidráulica. Tenemos constancia de la existencia de un ordo decurionum, ya que lo encontramos eximiendo el pago de la summa honoraria a un sevir (CIL II 1934).

En algunos casos, el emperador se presenta como promotor de las infraestructuras hidráulicas urbanas. En la península itálica existen ejemplos de intervención imperial en la construcción de acueductos en época altoimperial (De Rosa 2009). Tras un análisis de los casos conocidos, se observa cómo esta intervención y financiación ocurre en lugares en los que el emperador tiene un determinado interés por promocionar; concretamente, en colonias de veteranos, ciudades con importancia militar y comercial, principalmente portuarias, y en aquellas a las que le une algún tipo de vínculo familiar, clientelar o personal. En Hispania, la intervención imperial en la construcción de acueductos se intuye en las capitales de provincia como Augusta Emerita ( $A E$ 1984, 493; Hiernard y Álvarez 1982) o Corduba (CIL II ${ }^{2} / 7218$, Ventura y Pizarro 2010). Por otro lado, la actuación de la autoridad provincial en la ejecución de infraestructuras hidráulicas es poco conocida. Encontramos algún ejemplo de su intervención cuando acontece un problema técnico o financiero en la ejecución de la obra, como en el caso del acueducto de Nicomedia (Plin. Ep. 10.37-38, 90-91).

Por todo ello, en función de la importancia y categoría de Lacipo, parece más probable una promoción de sus construcciones hidráulicas procedente de la propia civitas, ya fuese de carácter público o privado.

En cuanto a la cronología del conjunto, no disponemos de datos para poder establecerla. El acueducto y los depósitos parecen corresponder a un mismo momento constructivo, empleándose materiales y técnicas similares, tanto en el opus incertum como en el signinum del revestimiento. Para proponer una cronología relativa, relacionamos el acueducto con el abastecimiento del presunto espacio público documentado en las excavaciones (Puertas 1982), en torno al cual se concentran las evidencias de hidráulica en la ciudad. Por tanto, cabría relacionar la construcción del acueducto con la urbanística de este lugar, datándose conjuntamente. En este sentido, se sugieren los siglos I-II d.C. como marco cronológico. Igualmente, el momento de abandono puede relacionarse con el ocaso de esta área, a la que iría destinada el agua. Una necrópolis datada en época tardoantigua se superpone a los niveles romanos, rompiendo y alterando los muros de la fase anterior (Puertas 1982: 26 y 35). Por ello, el momento de abandono de las estructuras hidráulicas debe datarse a partir de finales del siglo II o en el III d.C., en consonancia con el resto del urbanismo altoimperial. No debemos descartar un posible uso residual de estas estructuras en época tardoantigua, tal y como se ocurre con otros acueductos hispanos (Martínez 2012). Sin embargo parece poco probable, debido a la escasa entidad del asentamiento y la poca relevancia de la ocupación tardía de Lacipo. 
En general, la datación de los acueductos romanos es una cuestión compleja. Esto se debe a la escasez de excavaciones arqueológicas y a la falta de hallazgos de elementos que aporten una cronología absoluta. Por ello, como método de datación relativa, se ha establecido una relación entre momentos de construcción de los acueductos y de fundación o promoción cívica (Sánchez y Martínez 2010: 68-69). La correspondencia entre el cambio estatuario y la monumentalización es un fenómeno estudiado en las ciudades hispanas (Fear 1996: 220, Le Roux 1997: 335, Roddaz 1996, Keay 1998). Sin embargo, existen casos que contradicen esta generalidad. El acueducto de Conimbriga fue construido en época augustea (Etienne y Alarcão 1974, Dos Santos et al. 1994, Reis 2013, Sánchez y Martínez 2016: 69), mientras que la municipalización de la ciudad es de época flavia. Ocurre lo mismo en Igabrum (Cabra, Córdoba) (Goffaux 2013) y en otros casos en los que el momento de datación del aqua ducta no está tan claro, pero que apuntan a una ejecución anterior a la fecha de concesión de su estatuto cívico. Así sucedería en Ilipla (Niebla, Huelva), municipio flavio con acueducto julio-claudio (Campos et al. 2006: 347). Por tanto, no es posible generalizar la asociación entre monumentalización y concesión del estatuto urbano. Aunque en muchos casos fueran coetáneas, se ha confirmado que también pueden ser independientes, como sucedió en Cartima (Cártama, Málaga) (Gouffaux 2003: 146).

En cuanto a las cisternas a bagnarola, parecen corresponder, según su tipología, ubicación y función, a un momento cronológico previo (hipótesis ya apuntada por Rodríguez Oliva 2017: 60). Pueden indicar el tipo de aprovisionamiento que posee la ciudad con anterioridad a la construcción del acueducto. La situación topográfica del asentamiento, en altura, conlleva la falta de fuentes de captación. Esta práctica puede estar fosilizando un método de abastecimiento de época prerromana. Las cisternas, tanto comunitarias como privadas, son frecuentes en poblados de esta cronología (Mata 2009). Contamos con algunos ejemplos de cisternas a bagnarola en este tipo de asentamientos, como en el Cerro de la Cruz (Almedinilla, Córdoba), ubicadas en ámbito doméstico (Quesada et al. 2010). Más cercano geográficamente se encuentra el yacimiento de Cerro de las Naranjas (Jerez de la Frontera, Cádiz), donde la cisterna presenta un sistema constructivo muy parecido al que encontramos en Lacipo (Mata 2009).

Por tanto en esta ciudad, tras la introducción del acueducto, el método de recogida de aguas pluviales y almacenamiento en cisternas se habría mantenido.
En Pompeya, cuyo sistema de gestión de agua urbana es uno de los mejor conocidos del Imperio, se ha demostrado cómo el antiguo abastecimiento mediante cisternas domésticas sigue en funcionamiento tras la introducción del agua corriente (Dessales 2008).

\section{USOS DEL AGUA EN LA CIUDAD DE LACIPO}

En Lacipo encontramos un sistema de alimentación hídrica mixto. De una parte el agua es traída desde un manantial por el acueducto, que constituiría el aqua publica. Recordemos la preferencia en la Antigüedad por el agua proveniente de fuentes naturales para el abastecimiento urbano (Vitr. 8.6.12.) y la destinación a diferentes usos según la calidad de las aguas (Front. Aq. 2.92.; sobre el debate generado en torno al aqua ducta destinada al consumo humano véase Feijoo 2005). Sin embargo, no debemos desdeñar el valor simbólico de los acueductos como obra que representa una categoría y una posición de la urbe que la posee. Constituyen uno de los elementos que da forma a la ciudad romana, símbolo de romanización y poder (Leveau y Paillet 1976: 419-442, Sánchez y Martínez 2016: 59). Por otra parte, parece coexistir un sistema de recogida y almacenamiento de agua pluvial por medio de cisternae insertas en las edificaciones (depósitos 4 y 6). Aunque no podemos afirmar su función doméstica por la falta de datos arqueológicos, el agua recogida y contenida podría responder al modelo presente en otras ciudades romanas, en las que el aqua privata era la contenida en las cisternas pluviales (Dessales 2008).

Esto nos hace cuestionarnos sus distintas destinaciones y por tanto funciones. El aqua ducta parece tratarse más de un agua para usos concretos, relacionados con la vida pública de la ciudad, con el embellecimiento de la misma a través de sus fuentes ornamentales. También puede tener una función cultual, como demuestra el ejercicio del culto imperial y de la existencia de construcciones destinadas a ello. La relación del agua y este tipo de culto desarrollado en los principales ámbitos cívicos como el foro, ha sido estudiada en las ciudades hispanas (Reis 2010: 285-314). En estos espacios se ubican estructuras hidráulicas destinadas a la realización de ritos y ceremonias. En el caso que venimos analizando, la concentración de depósitos en un sector específico relacionado con la posible zona de acceso, puede estar indicando la presencia de un ámbito público y principal, posible foro. En esta área se situaría algún tipo de edificio donde se ejercería el culto al 
emperador y su familia, tal y como nos atestiguan las fuentes epigráficas ( $A E$ 1981, 504).

Asimismo, podemos relacionarlo con el uso simbólico y ornamental de los acueductos, en el espacio principal de la ciudad, o incluso con la existencia en esta zona de unos baños o termas. Este tipo de instalaciones requieren una gran cantidad de agua, por lo que algunos investigadores las han relacionado con el motivo de construcción de los acueductos (Leveau y Paillet 1976: 419-442). La existencia de fuentes decorativas para las que podía estar destinada el aqua ducta, nos la confirma el hallazgo de una estatua-fuente en bronce (Rodríguez Oliva 1976: 44). Se conservan dos fragmentos, uno correspondiente a la pierna derecha de una escultura y la segunda pieza, a un pedestal prismático, carente de zócalo y rematado por un friso. Sobre él tiene un jarrón en cuya parte superior, a ambos lados de un asa, se apoyan los dedos de una mano. Una perforación de sección circular, por donde discurría el agua que manaría de su boca, demuestra su funcionalidad. Esta estatua-fuente podría corresponder con una representación de Dyonisos, divinidad relacionada con las aguas superficiales (Rodríguez Oliva 1976).

En lo que respecta a la parte habitacional del asentamiento, no disponemos de datos y en consecuencia, tampoco de su disponibilidad de agua. En función del tamaño del asentamiento, las unidades habitacionales no debían ser numerosas, solo las propias de las principales familias que ostentan los cargos de administración del municipio. Aun así, la excavación completa del cerro corroboraría la hipótesis, con el conocimiento completo del patrón de asentamiento de la ciudad. Sin embargo la ciudad, por su fisonomía, parece acercarse más a entidades cívicas erigidas como centros políticos, administrativos y religioso, núcleos dinamizadores del territorio, aglutinadores de una población diseminada, asimilándose al modelo civitas sine urbem o civitas dispersa (Detlefsen 1873, Oller 2011, Houten 2017). Una de las principales características de este tipo de entidad cívica es contar con un centro monumental basado en uno o diversos edificios de carácter público de diferente tipo y funciones, sin evidencias materiales de una zona de hábitat en consonancia con la entidad monumental de dicho centro. Uno de estos ejemplos es la ciudad bética de Munigua (Villanueva del Río y Minas, Sevilla) (Oller 2011: 194). Era el centro cívico, político y administrativo de una comarca amplia, en la que la población se encontraba dispersa. En Baetica, el modelo urbano iniciado por César y culminado por los Flavios responde a colonias y municipios cuya función no era tanto la de lugares de hábitat de la población rural, sino más bien la de centros de reorganización administrativa del territorio (Rodríguez Neila 1994: 469470). En el caso de Munigua, constituía el lugar de representación de la comunidad, de control por parte del aparato administrativo aportado por la provincialización y el sistema de civitates romanas que lo integran. El agua aquí jugaba un papel importante desde el punto de vista ritual, religioso, cultual, ornamental y placentero, materializado en el santuario y en las termas (Schattner 2003, 2007).

\section{EVACUACIÓN DE LAS AGUAS RESIDUALES}

El ciclo del agua en Lacipo finalizaría con la evacuación de las aguas usadas y excedentarias. Las ciudades romanas contaban con métodos de saneamiento en función de la complejidad y extensión del entramado urbanístico que poseyeran. En aquellas abastecidas por acueductos, el aqua caduca de los lacus y salientes publici era empleada en la limpieza de las calles, cloacas y conducciones de desagüe, contribuyendo a mantener la salubritas (Front. Aq. 2.111.). Contamos con ejemplos de ciudades hispanas con un complejo sistema de canales de desagüe jerarquizado, situado bajo el entramado viario. Entre ellas destaca Corduba (Sánchez 2011), Italica (Jiménez 2011) o Emerita Augusta (Acero 2018). Ciudades más modestas también presentan sistemas de drenaje y evacuación de residuos. Es el caso de Baelo, donde se combinan colectores situados bajo los cardines con el aprovechamiento de la pendiente natural de la ladera sobre la que se emplaza la ciudad, para así desaguar las aguas por gravedad (Bernal et al. 2010).

En la civitas objeto de nuestro estudio, este proceso está testimoniado mediante el hallazgo de restos de canalizaciones destinadas a la evacuación de las aguas. Estos vestigios pueden estar indicando la existencia de una planificación urbana o incluso de un verdadero sistema de alcantarillado. En la excavación del edificio del sector sur, se constataron canalillos que conducían las aguas hacia los límites del cerro (Puertas 1982: 35). En los márgenes del mismo, localizamos una canalización más amplia, cubierta con grandes lajas de piedra a modo de cloaca (fig. 17). De la misma no se conserva su trazado completo, ni tampoco se conoce el lugar por donde evacúa el agua. Solo disponemos de un pequeño tramo cuya orientación es paralela al límite del cerro y por tanto del asentamiento (fig. 9). Esta canalización podría circundar la ciudad para verter las 


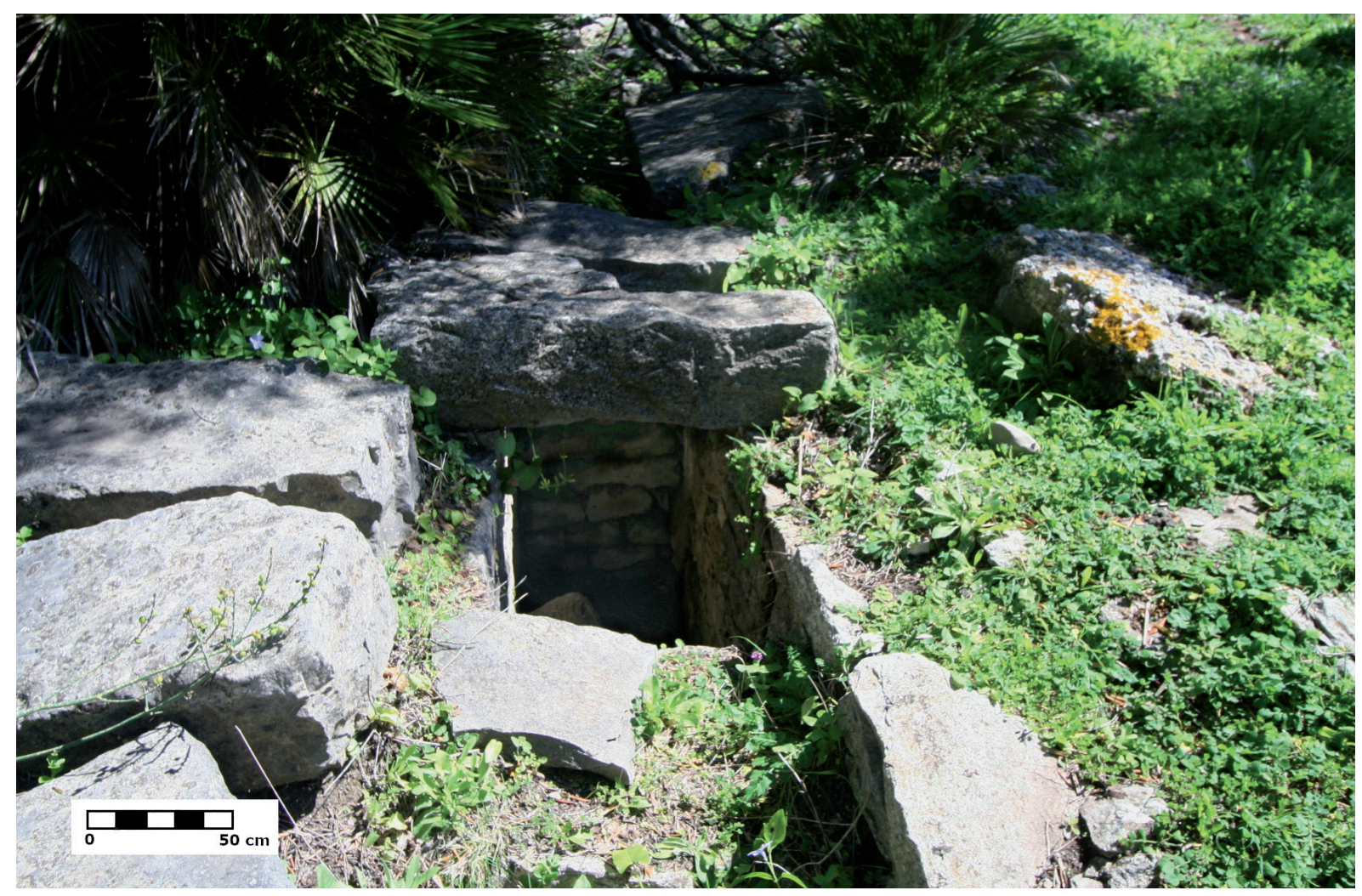

Figura 17. Restos conservados de la existencia de un alcantarillado o sistema de evacuación de aguas residuales.

aguas por alguna de sus laderas, quizás la norte, en donde se encuentra el arroyo Albarrán. Estas estructuras señalan la presencia de un sistema de regulación de las aguas usadas y de los excedentes pluviales. La ley municipal de Irni nos indica cómo los ediles eran los encargados del mantenimiento de las cloacas públicas (Lex Irn. 19.82., Liebeschuetz 2000: 57-59, Rodríguez Neila 2011: 38-44). Así en Lacipo, los representantes de la res publica serían los encargados del mantenimiento y la limpieza de las estructuras para el buen cumplimiento de su función.

\section{CONCLUSIONES}

El ciclo del agua en Lacipo se muestra completo: captación, conducción, distribución, uso y evacuación. Sin embargo, hasta el momento son escasos los testimonios de cada una de sus etapas. A través de este estudio observamos cómo la ciudad planifica, desde un ente superior, ya sea público o privado, un proyecto de captación, conducción y distribución de agua, que posteriormente hay que administrar y mantener para asegurar su correcto funcionamiento. Además, vemos cómo existió un interés por almacenar agua, tal y como sugiere la concentración de depósitos hidráulicos en una parte determinada del cerro. En cambio, el destino de esta agua nos es desconocido. Por un lado sería el consumo humano, que podría estar garantizado a través de la captación y almacenamiento pluvial. Por otro, estaría destinada al ejercicio de las diversas actividades cívicas y lúdicas propias de una ciudad romana, ya sean cultuales, ornamentales, higiénicas o placenteras. Sin embargo, el estudio de caso se encuentra incompleto, debido a la falta de investigaciones arqueológicas en el yacimiento. Su realización aportaría un conocimiento más detallado de la fisonomía urbana y de su trayectoria cronológica. Aun así, el asentamiento muestra las características de un núcleo urbano de pequeñas dimensiones e importancia limitada. Mediante el análisis de los vestigios visibles hemos comprobado cómo se ponen en práctica los conocimientos hidráulicos romanos en los núcleos poblacionales más modestos, y cómo se dotan de los elementos propios de una civitas, adoptando una verdadera cultura del agua romana. 


\section{Agradecimientos}

Este trabajo se ha realizado en el marco del proyecto Riparia 2. La Interacción histórica sociedad-medio ambiente: humedales y espacios lacustres en la Bética romana. HAR2016-77724-P, Ministerio de Economía y Competitividad, Gobierno de España.

Mis más sinceros agradecimientos van dirigidos al profesor Dr. D. Lázaro Lagóstena por su participación en la visita realizada al yacimiento arqueológico, cuyos resultados son expuestos en este artículo, y por las ideas aportadas. Igualmente, quiero reconocer el apoyo del investigador D. Pedro Trapero a los trabajos realizados en el yacimiento y a D. Javier Martos, gran conocedor de la zona, por la aportación desinteresada de datos geográficos, históricos y arqueológicos, y por su disposición a acompañarnos y mostrarnos los restos arqueológicos durante las visitas realizadas.

\section{BIBLIOGRAFÍA}

Acero, J. (2018): La gestión de los residuos en Augusta Emerita. Siglos I a.C.-VII d.C. Anejos de Archivo Español de Arqueología LXXXII. Madrid, Consejo Superior de Investigaciones Científicas.

Adams, J.P. y Varène, P. (2008): "Le castellum aquae de Pompéi, étude architecturale". Revue Archéologique 45-1: 37-72.

Almagro, A. (2002): "El acueducto de Albarracín a Cella (Teruel)", en Artifex. Ingeniería romana en España: 212-240. Madrid, Ministerio de Fomento, Fundación Juanelo Turriano.

Belfaida, A. (2000): "Eau et évergétisme en Afrique romaine: témoignages épigraphiques", en M. Khanoussi, P. Ruggeri y C. Vismara (eds.), L'Africa romana. Geografia, viaggiatori, militari nel Maghreb: alle origini dell'archeologia nel Nord Africa, vol. II: 1589-1601. Dejerba (1998), Roma, Carocci.

Beltrán, A. (1977): "Las obras hidráulicas de los Bañales", en Symposium de arqueología romana, Bimilenario de Segovia: 91-129. Segovia (1974), Barcelona, Universidad de Barcelona, Instituto de Prehistoria y Arqueología.

Bernal D.; Arévalo, A.; Muñoz, A.; García, I.; Bustamante, M. y Sáez, A. (2011): "Baelo Claudia”, en J.A. Remolà y J. Acero (eds.), La gestión de los residuos urbanos en Hispania. Xavier Dupré Raventós (1956-2006). In memoriam. Anejos de Archivo Español de Arqueología LXXXII: 65-92. Mérida, Consejo Superior de Investigaciones Científicas.
Bonetto, J.; Cespa, S. y Erdas S.V. (2012): “Approvvigionamento idrico a Nora: nuovi dati sulle cisterne", en M.B. Cocco, A. Gavini y A. Ibba (eds.), L'Africa romana. Trasformazione dei paesaggi del potere nell'Africa settentrionale fino alla fine del mondo antico, vol. III: 2591-2624. Sassari (2010), Roma, Carocci.

Borau, L. (2015): "Difusión de modelos romanos: particularidades técnicas del sistema de abastecimiento de agua a Baelo Claudia". Archivo Español de Arqueología 88: 149-169. DOI: <http://dx.doi. org/10.3989/aespa.088.015.008>.

Bravo, S. (2010): Dinámicas de control ideológico y territorial en el Estrecho de Gibraltar en épocas fenicia, púnica y romana. Tesis doctoral, UNED, Facultad de Geografía e Historia, disponible en línea: <http://e-spacio.uned.es/fez/ view/tesisuned:GeoHis-Sbravo> (12 de febrero de 2019).

Bruun, C. (1991): Water Supply of Ancient World. A Study of Roman Imperial Administration. Helsinki, Societas Scientiarum Fennica.

Bukowiecki, E.; Dessales, H. y Dubouloz, J. (2008): Ostie, l'eau dans la ville: chateaux d'eau et réseau d'adduction. Roma, École Française de Rome.

Burés, L. (1998): Les estructures hydràuliques a la ciutat antiga: l'exemple d'Empúries. Barcelona, $\mathrm{Mu}-$ seu d'Arqueologia de Catalunya-Empúries.

Campos, J.M.; Gómez, F. y Pérez, J.A. (2006): Ilipla. Niebla. Evolución urbana y ocupación del territorio. Huelva, Universidad de Huelva.

Casares, Planimetría 1875. Ayuntamiento de Casares, provincia de Málaga, $12^{\mathrm{a}}$ Brigada, bosquejos planimétricos, Instituto Geográfico y Estadístico, colocado, dibujado y construido por el topógrafo Darío Varela-Escala 1:25.000. Instituto Geográfico Nacional, Madrid, IECA1989004108. Digitalizado por Catálogo digital de Cartografía Histórica de Andalucía, Instituto de Estadística y Cartografía de Andalucía. Consejería de Economía, Innovación, Ciencia y Empleo. <http://www.juntadeandalucia. es/institutodeestadisticaycartografia/cartoteca/buscar/getisbn/query/casares/autor/titulo/lugargeo/materias/fechadesde/fechahasta/buscar/Buscar/startid/10/id/3982> (29 de marzo de 2019).

Chanson, H. (2000): “A Hydraulic Study of Roman Aqueduct and Water Supply". Australian Journal of Water Resources 4, n 2: 111-120.

Corbier, M. (1984): "De Volsinii a Sestinum: Cura aquae et évergétisme municipal de 1'eau en Italie". Revue des Études Latines 62: 236-274. 
Corzo, S. (2005): "La ceca romana de Lacipo: análisis y nuevo hallazgo", en C. Alfaro, C. Marcos y P. Otero (eds.), XIII Congreso Internacional de Numismática, vol. 1: 499-502. Madrid (2002), Madrid, Ministerio de Cultura, Subdirección General de Publicaciones, Información y Documentación.

Dessales, H. (2008): “Des usages de l'eau aux évaluations démographiques: l'exemple de Pompéi”. Histoire Urbaine 22: 25-39.

Dessales, H. (2013): Le partage de l'eau. Fontaines et distribution hydraulique dans l'habitat urbain de l'Italie romaine. Roma, École Française de Rome.

Detlefsen, D. (1873): “Die Geographie der tarraconensiscen Provinz bei Plinius (Plin. nat. Hist. 3, 18-30/ 76-79; 4, 110-112)". Philologus 32: 600-668.

Dos Santos, C.J.; Pessoa, M.; Madeira, J.L.; Tröger, U. y Dos Santos, M.M. (1994): “Os pólos de captaçao de agua de Conimbriga”. Conimbriga 32-33: 171179.

Eschebach, H. (1977): "Die Gebrauchwasserer sorgung des Pompeii”. Antike Welt 10: 3-24.

Étienne, R. y Alarcão, J. (1974): “O aqueduto romano de Conímbriga”, en Actas do III Congreso Nacional de Arqueología, vol. 1: 283-292. Oporto (1973), Oporto, Junta Nacional de Educação.

Fabre, G.; Fiches, J.L.; Paillet, J.L. (eds.) (2000 [1991]): L'Aqueduc de Nimes et le Pont de Gard, archaeolgie, geosysteme et histoire. París, CNRS éditions ( $2^{\mathrm{a}}$ ed. rev.).

Fear, A.T. (1996): Rome and Baetica. Urbanization in Southern Spain, c. 50 B.C.-A.D. 150. Oxford, Clarendon Press.

Feijoo, S. (2005): "Las presas y los acueductos de agua potable una asociación incompatible en la antigüedad. El abastecimiento en Augusta Emerita", en T. Nogales (ed.), Augusta Emerita. Territorios, Espacios, Imágenes y Gentes en Lusitania Romana: 173205. Mérida, Museo Nacional de Arte Romano.

Fishwick, D. (1993): The Imperial Cult in the Latin West: Studies in the Ruler Cult of the Western Provinces of the Roman Empire I, 1 y 2, II, 1 y 2. Leiden, Brill.

García Merino, C. (2006): “Avance al estudio del acueducto de Uxama", en I. Moreno (ed.), Nuevos elementos de ingeniería romana. III Congreso de las Obras Públicas Romanas: 167-194. Valladolid, Consejería de Cultura y Turismo.

García Merino, C. (2010): "Las cisternas y la elevación de agua del acueducto en Uxama", en I. Moreno (ed.), Las técnicas y las construcciones en la ingeniería romana. V Congreso de las obras públicas romanas: 283-298. Córdoba (2010), Madrid, Fundación de la Ingeniería Técnica de Obras Públicas.

García García, M.A. (2007): “Aqua Hispalensis: Primer avance sobre la excavación de la cisterna romana de Plaza de la Pescadería (Sevilla)". Romvla 6: 125-142.

Gener, J.M. (2001): "Puesta en valor del yacimiento arqueológico de Sierra Aznar (Arcos de la Frontera). Limpieza, consolidación y documentación". Anuario Arqueológico de Andalucía 1997, III: 44-52.

Goffaux, B. (2003): "Promotions juridiques et monumentalisation des cités hispano-romaines". Saldvie 3: 143-161.

Goffaux, B. (2013): “CIL II2/5, 316 (Igabrum) y la cronología de los primeros flamines provinciales de la Bética". Archivo Español de Arqueología 86: 261-278. $<$ https://doi.org/10.3989/aespa.086.013.015>.

Guerrero, L. (2001): “Intervención arqueológica de urgencia en la ciudad romana de Sierra Aznar, Arcos de la Frontera (Cádiz)". Anuario Arqueológico de Andalucía 1998, I: 32-37.

Hiernard, J. y Álvarez, J.M. (1982): “Aqua Augusta, una inscripción de letras de bronce en Mérida”. Sautuola 3: 221-229.

Hodge, A.T. (2002 [1992]): Roman Aqueducts and Water Supply. London, Duckworth.

Houten, P. (2017): "El papel de las aglomeraciones secundarias en las civitates dispersas", en S. Panzram (ed.), Oppidum-civitas-urbs. Städteforschung auf der Iberischen Halbinsel zwischen Rom und al-Andalus. Geschichte und Kultur der Iberischen Welt 12: 681-708. Münster, LIT-Verlag.

Jiménez, A. (1973): "Los acueductos de Baelo Claudia (Bolonia, Cádiz)". Habis 4: 273-293. <https:// doi.org/10.12795/Habis.1973.i04.15>.

Jiménez, A. (2011): "Italica. La red de alcantarillado", en J.A. Remolà y J. Acero (eds.), La gestión de los residuos urbanos en Hispania. Xavier Dupré Raventós (1956-2006). In memoriam. Anejos de AEspA LX: 145-154. Mérida, Consejo Superior de Investigaciones Científicas.

Jiménez, J.L. (1995): “Referencias historiográficas sobre el Acueducto de Peña Cortada (Los Serranos, Valencia)". Arse 28-29: 217-234.

Keay, S. (1998): "The development of towns in Early Roman Baetica", en S. Keay (ed.), The archaeology of early Roman Baetica. Journal of Roman Archeology, suppl. 29: 55-85. Rhode Island-Portsmouth, Editorial Committee of the Roman of Roman Archaeology. 
Le Roux, P. (1997): Le Haut-Empire romain en Occident d'Auguste: aux Sévères 31 av. J.-C.-235 apr. $J .-C$. París, Éditions du Seuil.

Leveau, P y Paillet, J.L. (1976): L'alimentation en eau de Caesarea de Mauritania et l'aqueduc de Cherchell: 419-442. París, L'Harmattan.

Liebeschuetz, W. (2000): "Rubbish Disponsal in Greek and Roman Cities", en X. Duprés y J.A. Remolà (eds.), Sordes Urbis. La eliminación de residuos en la ciudad romana. Actas de la reunión de Roma: 5161. Roma (1996), Roma, L'Erma di Bretschneider.

Malissard, A. (1994): Les Romains et l'eau: fontaines, salles de bains, thermes, égouts, aqueducs. París: Les Belles Lettres.

Martín Bueno, M.A. (1975): "El abastecimiento y distribución de agua al Municipium Augusta Bilbilis". Hispania Antiqua 5: 205-222.

Martínez, J. (2012): "Reuse, Repair and Reconstruction. Functioning aqueducts in post-Roman Spain", en B. Jervis y A. Kyle (eds.), Make-do and Mend: Arquaeologies of Compromise, Repair and Reuse. British Archaeological Report International Series 2408: 27-42. Oxford, Archaeopress.

Mata, E. (2009): "Precedentes de los aprovechamientos hídricos en la antigüedad gaditana. El mundo turdetano", en L.G. Lagóstena y F.B. Zuleta (eds.), La captación, los usos y la administración del agua en Baetica: estudios sobre el abastecimiento hídrico en comunidades cívicas del Conventus Gaditanus: 115-170. Cádiz, Universidad de Cádiz, Seminario Agustín de Horozco.

Mata, E.; Zuleta, F. B.; Lagóstena L.G. y Cobos. L.M. (2010): "Sierra Aznar ¿Castellum aquae o caput aquae?”, en L.G. Lagóstena, J.L. Cañizar y L. Pons (eds.), Aquam perducendam curavit: captación, uso y administración del agua en las ciudades de la Bética y el occidente romano: 261-270. Cádiz, Universidad de Cádiz, Seminario Agustín de Horozco.

Mayer, M. (1996): "El evergetismo referente a las aguas en Hispania”, en M. Mayer y M. Miró (ed.), Homenatge a F. Giunta: committenza e committenti tra antichità e alto medievo: actes del XVIe workshop. Erice (1994), Barcelona, Promociones y Publicaciones Universitarias.

Melchor, E. (1994): El mecenazgo cívico en la Bética. la contribución de los evergetas al desarrollo de la vida municipal. Córdoba, Instituto de Historia de Andalucía.

Mezzolani, A. (1997): “L'approvvigionamento idrico a Tharros: note preliminari”, en E. Acquaro, G.M. Francisi, G.M. Ingo y L.I. Manfredi (eds.), Progetto
Tharros: 121-130. Roma, Consiglio Nazionale delle Ricerche.

Montañés, S. y Montañés, M. (2010): “Actuación arqueológica de urgencia. C/ San Juan de Ribera y Alfonso el Sabio. Alcalá de los Gazules (Cádiz)". Аnuario Arqueológico de Andalucía 2006, Cádiz: 504-509.

Mora, B. (1990): "Malaca, Acinipo y Lacipo: tres cecas monetales en los territorios malacitanos". Jábega $67: 3-12$.

Navarro, I. (2006): "El abastecimiento de agua a una ciudad romana: Lacipo (Casares)", en A. Serrano, F. López y F.A. López (coords.), Aqua Nostra, Agua de todos. El agua en la Costa Occidental Malagueña: 99-103. Marbella, Cilniana.

Oleson, J.P (2010): The Oxford Handbook of Engineering and Technology in the Classical World. Oxford, Oxford University Press.

Oller, J. (2011): "La ciudad sin ciudad: la civitas sine urbe como elemento de control territorial". Estrat Critic 5/1: 190-203.

Peleg, Y. (2000): "The characteristics of water distribution in Roman towns", en Cura Aquarum in Sicilia. Proceeding of the Tenth International Congress on the History of Water Management and Hydraulic Engineering in the Mediterranean Region: 241-246. Siracusa (1998), Leiden, Stichting Babesch.

Pellicer, M. (1982): "Excavaciones en Itálica (19781979). Murallas, cloacas y cisterna”, en Itálica (Santiponce, Sevilla). Actas de las Primeras Jornadas sobre Excavaciones Arqueológicas en Itálica. Excavaciones Arqueológicas en España 121: $205-$ 224. Sevilla (1980), Madrid, Subdirección General de Arqueología y Etnografía.

Proyecto "Conoce tus Fuentes, Fuentes y Manantiales de Andalucía". Instituto Universitario de Investigación del Agua de la Universidad de Granada. $<$ http://www.conocetusfuentes.com/home.php>, [8 de marzo de 2019].

Puertas, R. (1979): "Nuevo epígrafe monumental de Lacipo". Mainake 1: 99-104.

Puertas, R. (1982): Excavaciones arqueológicas en Lacipo (Casares, Málaga). Campañas de 1975 y 1976. Madrid, Ministerio de Cultura, Dirección General de Bellas Artes y Archivos. Subdirección General de Arqueología y Etnografía.

Puertas, R. y Rodríguez Oliva, P. (1979): “La ciudad de Lacipo y sus monedas". Mainake 1: 105-127.

Quesada, F.; Kavanagh E. y Moralejo, J. (2010): “El asentamiento de época ibérica en el Cerro de la Cruz". Oikos 2: 75-97. 
Reis, M.P. (2010): “Tanques, fontes e espelhos de água nos foro lusitanos", en T. Nogales (ed.), Ciudad y foro en Lusitania Romana: 285-363. Mérida, Museo Nacional de Arte Romano.

Reis, M.P. (2013): “Gestão e Rede Hidráulica de Conimbriga. A domus de Tancinus e construções anexas", en J. López (ed.), Conimbriga tardo-antigua y medieval. Excavaciones arqueológicas en la domus tancinus (2004-2008) (Condeixa-a-Velha, Portugal). British Archaeological Report 2466: 25-36. Oxford, Archeopress.

Ricciardi, M.A. y Scrinari, V.S.M. (1996): La civiltà dell'acqua in Ostia antica, 2 vol. Roma, Fratelli Palombi.

Roddaz, J.M. (1996): "Pouvoir et provinces: remarques sur la politique de colonisation et de municipalisation de Rome dans la Penínsule Ibérique entre César et Auguste", en E. Ortiz de Urbina y J. Santos (eds.), Teoría y práctica del ordenamiento municipal en Hispania. Actas del Simposium. Veleia. Anejos, Series, Acta III: 13-25. Vitoria-Gasteiz (1993), Vitoria-Gasteiz, Instituto de Ciencias de la Antigüedad, Universidad del País Vasco.

Rodríguez Neila, J.F. (1988): “Aqua publica y política municipal romana”. Gerión 6: 223-252.

Rodríguez Neila, J.F. (1994): “Ciudad y territorio de la provincia romana de la Bética". Florentia Iliberritana 4-5: 445-485.

Rodríguez Neila, J.F. (2011): "Problemas medioambientales urbanos en el mundo romano", en J.A. Remolá, J. Acero (eds.), La gestión de los residuos urbanos en Hispania. Xavier Dupré Raventós (1956-2006). In memoriam. Anejos de AEspA LX: 27-49. Mérida, Consejo Superior de Investigaciones Científicas.

Rodríguez Oliva, P. (1976): "Una estatua fuente de Lacipo”. Jábega 13: 43-46.

Rodríguez Oliva, P. (2006): "Unas inscripciones funerarias de Lacipo (Casares, Málaga) que evocan el establecimiento en Carteia (San Roque, Cádiz) de la Colonia Latina Libertinorum". Baetica 28-2: 123-158.

Rodríguez Oliva, P. (2017): "El yacimiento arqueológico de Lacipo (Casares, Málaga)". Revista PH 92: 52-61.

Saborido, S. (2006): "El agua en Casares", en A. Serrano, F. López y F.A. López (coords.), Aqua Nostra,
Agua de todos. El agua en la Costa Occidental Malagueña: 96-98. Marbella, Asociación Cilniana.

Sánchez, E. y Martínez, J. (2016): Los acueductos de Hispania, construcción y abandono. Madrid, Fundación Juanelo Turriano.

Schattner, T.G. (2003): Munigua, cuarenta años de investigaciones. Sevilla-Madrid, Consejería de Cultura, Instituto Arqueológico Alemán.

Schattner, T.G. y Ovejero, G. (2007): “Agua en Munigua”, en J. Mangas y S. Martínez Caballero (eds.), El agua y las ciudades romanas: 99-132. Móstoles, Ediciones 2007.

Sillières, P. (1997): Baelo Claudia. Una ciudad romana de la Bética. Madrid, Casa de Velázquez.

Soto Jiménez, L. (1979): "Lacipo. Ciudad turdetana y romana". Jábega 28: 3-7.

Tabales, M.A.; Oliva, P.; Mora, G.; Huarte, R.; Graciani, A.; Calama, J.M. y Pérez A. (2005): "Investigaciones arqueológicas en el Castillo de Jimena de la Frontera. Cádiz. Fase I (2002)". Anuario Arqueológico de Andalucía 2002, III, tomo I: 131-155.

Tomassetti, J.M.; Suárez, J. y Martos J. (e.p.): “Prospección arqueológica superficial del término municipal de Casares (Málaga)". Anuario Arqueológico de Andalucía 2010.

Ventura, A. (1996): El abastecimiento de agua a la Córdoba romana II: acueductos, ciclo de distribución y urbanismo. Córdoba, Servicio de Publicaciones, Universidad de Córdoba.

Ventura, A. y Pizarro, G. (2010): "El Aqua Augusta (Acueducto de Valdepuentes) y el abastecimiento de agua a Colonia Patricia Corduba: Investigaciones Recientes (2000-2010)", en I. Moreno (ed.), Las técnicas y las construcciones en la ingeniería romana: V Congreso de las Obras Públicas Romanas: 177-203. Córdoba (2010), Madrid, Fundación de la Ingeniería Técnica de Obras Públicas.

Villar, F. (2000): Indoeuropeos y no indoeuropeos en la Hispania prerromana. Salamanca, Universidad de Salamanca.

Wilson, A. (2001): "Urban water storage, distribution and usage in Roman North Africa", en A.O. Koloski-Ostrow (ed.), Water use and hydraulics in the Roman city: 83-96. Dubuque-Iowa, Kendall / Hunt Publishing Compani. 